\title{
INNOVATION AND EFFICIENCY
}

Heinz-Dieter Haustein, Harry Maier, and Luitpold Uhlmann

International Institute for Applied Systems Analysis, Austria

RR-81-7

May 1981

INTERNATIONAL INSTITUTE FOR APPLIED SYSTEMS ANALYSIS

Laxenburg, Austria 
International Standard Book Number 3-7045-0008-9

Research Reports, which record research conducted at IIASA, are independently reviewed before publication. However, the views and opinions they express are not necessarily those of the Institute or the National Member Organizations that support it.

\section{Copyright $\odot 1981$}

International Institute for Applied Systems Analysis

All rights reserved. No part of this publication may be reproduced or transmitted in any form or by any means, electronic or mechanical, including photocopy, recording, or any information storage or retrieval system, without permission in writing from the publisher. 


\section{FOREWORD}

The Management and Technology Area of the International Institute for Applied Systems Analysis (IIASA) is devoted to studying and evaluating the challenges that technological change and its counterpart, technological stagnation, pose to people, institutions, and societies. Another objective is to identify effective policies and strategies to counter these challenges.

Nevertheless, a formal program of research into the problems and processes of innovation was not instituted at IIASA until 1979. Although single-discipline studies were not uncommon, little multidisciplinary applied systems analysis work had been attempted in this field. IIASA's initial task was, therefore, to develop a methodological basis applicable to innovation problems in several countries with different social systems. This was done in cooperation with scholars and experts in the USA, USSR, UK, Czechoslovakia, GDR, FRG, Sweden, Hungary, the Netherlands, Poland, Japan, and Bulgaria.

The authors of this report describe their approach to innovation research and propose ideas for further work at Laxenburg in the field of innovation and industrial strategy.

As the authors note, innovation is not a goal in itself. By titling their report Innovation and Efficiency, they recognize that innovation must aim at higher efficiency, which means either satisfying needs better with given resources or saving resources at a given level of satisfaction.

ALEC LEE

Chairman

Management and Technology Area 



\section{CONTENTS}

$\begin{array}{ll}\text { SUMMARY } & 1\end{array}$

1 MEASURING EFFICIENCY IN THE INNOVATION PROCESS 1

1.1 Principal Indicators of Efficiency 1

$\begin{array}{ll}1.2 & \text { Relative Efficiency } \\ & 13\end{array}$

2 FACTORS INFLUENCING INNOVATIVE ACTIVITIES:

$\begin{array}{ll}\text { AN ANALYTIC APPROACH } & 17\end{array}$

$\begin{array}{ll}2.1 \text { A Model of the Innovation Process } & 17\end{array}$

$\begin{array}{ll}2.2 \text { Factors Influencing Innovative Activities } & 21\end{array}$

$\begin{array}{ll}2.3 \text { Efficacy of Factors } & 24\end{array}$

2.4 Control of Factors $\quad 26$

2.5 Classifying Innovations by Efficiency 28

2.6 The Effect of Basic and Improvement-Related Innovations on Efficiency 30

3 INDUSTRIAL ORGANIZATIONS AND EFFICIENCY:

A SYNTHETIC APPROACH 41

3.1 Innovative Activities in the Life Cycles of Industrial Organizations 41

3.2 Determinants of Innovative Activities in Industrial Organizations 44

3.3 Innovation and the Efficiency Cycle 54

4 CONCLUSIONS $\quad 57$

$\begin{array}{lr}\text { REFERENCES } & 58\end{array}$

APPENDIX A A Method for Calculating the Time Needed to Equalize Productivity Levels in Two Countries $\quad 59$

APPENDIX B The Efficacy of Factors Influencing Innovative Activities 62 



\section{INNOVATION AND EFFICIENCY}

Heinz-Dieter Haustein, Harry Maier, and Luitpold Uhlmann

International Institute for Applied Systems Analysis, Austria

\section{SUMMARY}

Innovation is a complex phenomenon that involves all spheres of technological, economic, and social activity, from research and development to investment, production, and application. In the management of innovation the relationship between innovation and efficiency is the key issue. In this report, therefore, we elaborate on a method for measuring efficiency in the innovation process. The core of our concept of efficiency is the link between the efficiency of the production unit that has adopted an innovation /dynamic efficiency) and the efficiency of the entire production field within which production units must act (average efficiency). The development of relative efficiency is connected to differences between basic, improvement-related, and pseudo innovations and to the decisionmaking environment for managers.

Factors influencing innovative activities follow a continuum of efficacy ranging from inhibiting to strongly promoting innovative activities. Looking at the innovation process from the standpoint of the innovating system, we distinguish major determinants of performance and then compare the performance of industrial organizations through a profile showing these determinants in research and development, production, and marketing and in management at all stages.

\section{MEASURING EFFICIENCY IN THE INNOVATION PROCESS}

\subsection{Principal Indicators of Efficiency}

Before presenting our model of the innovation process, we would like to describe the economic environment of innovations; without knowing the needs of and possibilities 
offered by this environment, one cannot understand the mechanism of technological change. The results of interactions between innovations and their environment are usually measured in terms of economic efficiency. In this report, therefore, we focus our attention on the problem of efficiency.

The measurement of efficiency in socioeconomic and technical-economic processes is a wide and comprehensively explored field. We differentiate in this report among technical efficacy, economic efficiency, and social effectiveness. Specific measures of technical efficacy are clearly defined and verifiable, but it is difficult to give general indicators for the technical efficacy of such products as automobiles, washing machines, and television sets. This generalization is even more true for measures of economic efficiency, which are by definition more aggregate than are technical indicators. Here we also encounter other problems: the difficulty of clearly adjoining elements to defined sets, the complicated procedure of statistical inquiry, and the lost contact between user and producer of data. Yet the measurement of social effectiveness is the most complicated, as social welfare and social climate cannot be measured successfully by the monetary indicators that are so useful in economics.

Innovation is a complex phenomenon that involves all spheres of technological, economic, and social activity, from research and development to investment, production, and application. In the early stages there are only two general indicators of innovative efficiency, which can be evaluated and predicted in rough variants (see Fig. 1). These are the level of technology and the desired range of application. These indicators are combined into certain coefficients and are connected with recognized needs, time limitations and competitive pressures, and available resources. The level of technology and range of application determine the compatibility or interference with existing equipment and skills, degree of interdependence, degree of complexity, and scale. For these coefficients we need additional information that is not available during the first stages of research and development. As the innovation process progresses, however, we are able to calculate the risk factor, development time, lifetime, and resource requirements. We should then gradually make the previously mentioned coefficients more precise. Later, we can calculate in monetary measures the economic benefits and expenditures and can determine other indicators of economic and social efficiency.

Owing to the interference of the new technology with existing equipment and skills, however, it is not easy to isolate the efficiency of the innovation from that of the production unit introducing the new technology. The only available solution to this problem is to compare an innovating unit with a noninnovating unit, but neither the results of interference with existing equipment and skills nor the effects of new elements can be isolated.

It is difficult enough to measure efficiency in comparing similar industries or countries, but we encounter many more problems in trying to compare those under different social systems; both the goals and underlying mechanisms of socioeconomic actions and the reference system for measuring efficiency are different. Table 1 suggests that, at least for some indicators, there are no great differences between market and planned economies. We must ensure, however, that similar indicators are used for different goals in both systems and that in planned economies these indicators are calculated in a uniform way within the planning process connecting all levels from the plant to the national economy. A common reference system is needed and is plausible primarily

- In fields involving such cooperative action as trade, exchange of technologies, and investigation of solutions to world problems

- At the level of intermediate goals 


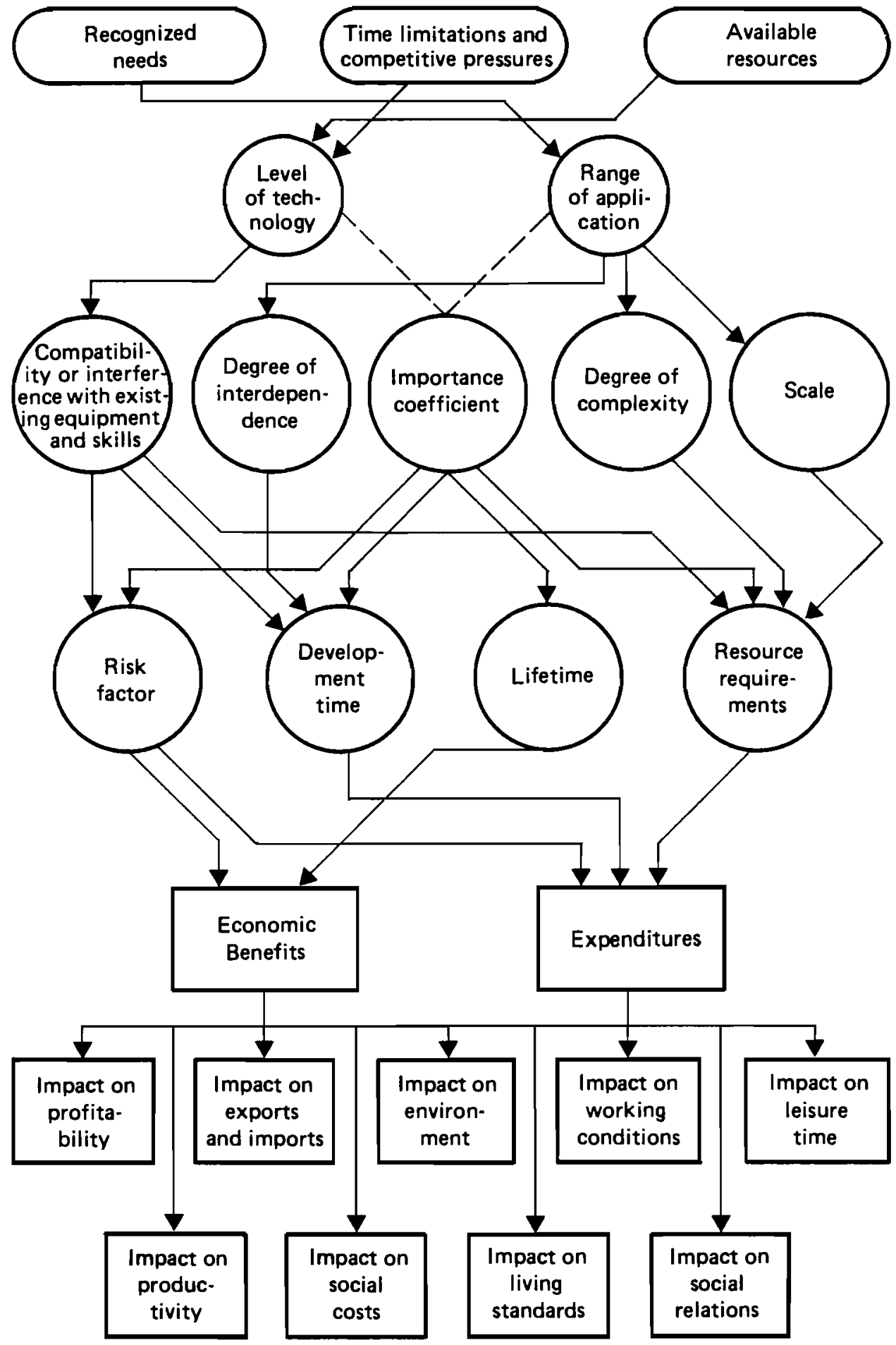

FIGURE 1 Indicators of innovative efficiency. 
TABLE 1 Measures of efficiency in market and planned economies at the company and national levels.

\begin{tabular}{|c|c|c|}
\hline \multirow[b]{2}{*}{ Level } & \multicolumn{2}{|l|}{ Measures of efficiency } \\
\hline & Market economy & Planned economy \\
\hline \multirow[t]{10}{*}{ Company } & Grow th rate (sales and profits) & Growth rate (net product) \\
\hline & Productivity (labor and capital) & Productivity (labor) \\
\hline & Return on book value & Return on funds \\
\hline & Profit margin (as percent of sales) & - \\
\hline & Earnings per share & - \\
\hline & Market share & - \\
\hline & - & Export profitability \\
\hline & -. & Cost factor \\
\hline & - & Material intensity of production \\
\hline & - & Capital coefficient (output per unit of funds) \\
\hline \multirow[t]{4}{*}{ National } & Growth rate (national income) & Growth rate (national income) \\
\hline & Productivity (labor) & Productivity (labor) \\
\hline & Balance of payments & Balance of payments \\
\hline & Capital coefficient & Capital coefficient \\
\hline
\end{tabular}

One of the most important intermediate goals in both kinds of economy is productivity. It is generally accepted that productivity growth rates over a long period reflect the true economic performance of an industry or of a nation. Data on productivity growth rates are available in all countries and are more comparable than are indicators of profitability. The development of labor productivity could be an important indicator of a country's technological innovativeness, but we must also take into account the constraints connected with this indicator.

$$
\text { Labor productivity }=\frac{\text { Gross product }}{\text { Number of employees }} \text { or } \frac{\text { Net product }}{\text { Working hours }}
$$

Statistical details show that the gross domestic product (GDP) is not the same in the Organisation for Economic Co-operation and Development (OECD) and Council for Mutual Economic Assistance (CMEA) countries. CMEA countries include material input from outside the firm, while OECD countries do not. On the other hand, the figures of CMEA countries include only goods and so-called productive services - not banking or insurance operations, rent, and similar factors. Figure 2 shows the principal similarities and differences in methodology, while Table 2 gives a practical example. The net product according to the methodology of planned economies is 20 to 30 percent lower than the same net product according to the methodology of market economies. On the level of the industry, the methodologies are more similar, and the production value includes sales and the changes in inventories of intermediate products. We also find differences in methodology with respect to the number of employees; while apprentices are included as employees in OECD countries, they are not in CMEA countries.

We cannot, therefore, expect the official productivity statistics of OECD and CMEA countries to give us a complete picture. However, the differences counteract and neutralize each other in part; this is particularly evident if we investigate growth rates. In Table 3 we present industrial productivity growth rates in major developed countries for 1963-1973, 1973-1977, 1978, and 1979. Figure 3 shows the decline in productivity growth rates for 


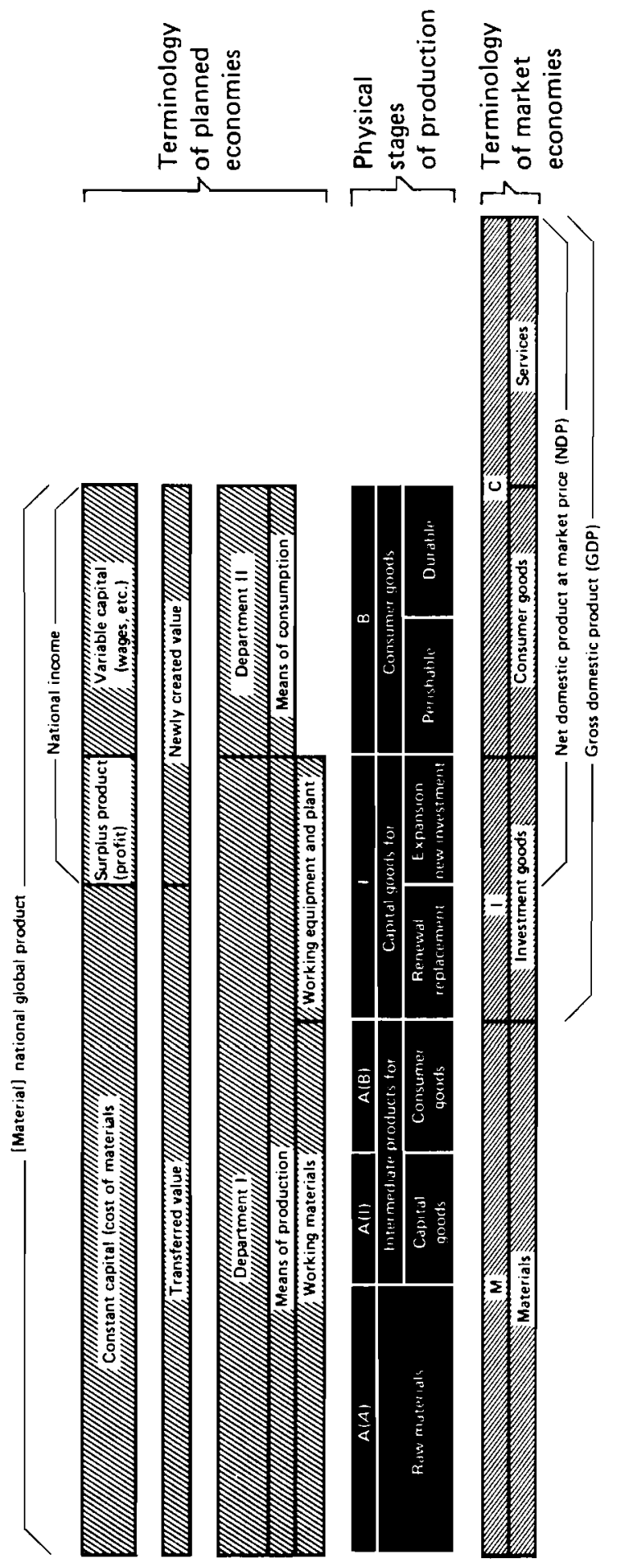

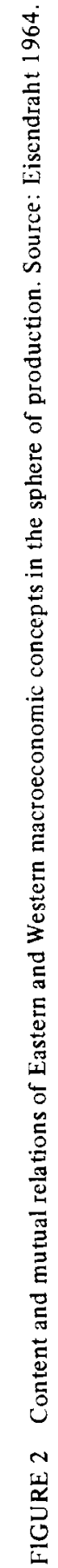


TABLE 2 Comparison of national income per inhabitant and national income in the USA, USSR, FRG, and Japan, 1977.

\begin{tabular}{|c|c|c|c|c|c|c|c|c|c|c|}
\hline \multirow[b]{4}{*}{ Country } & \multicolumn{6}{|c|}{ National income per inhabitant } & \multicolumn{4}{|c|}{ National income } \\
\hline & \multirow{2}{*}{\multicolumn{2}{|c|}{$\begin{array}{l}\text { According to the } \\
\text { methodology of } \\
\text { market econo- } \\
\text { mies, including } \\
\text { nonproductive } \\
\text { sector (services) } \\
\text { At official } \\
\text { exchange rate }\end{array}$}} & \multicolumn{4}{|c|}{$\begin{array}{l}\text { According to the methodology of } \\
\text { planned economies, excluding } \\
\text { nonproductive sector (services) }\end{array}$} & \multirow{2}{*}{\multicolumn{2}{|c|}{$\begin{array}{l}\text { At official } \\
\text { exchange rate }\end{array}$}} & \multirow{2}{*}{\multicolumn{2}{|c|}{$\begin{array}{l}\text { At purchasing } \\
\text { power value }\end{array}$}} \\
\hline & & & \multicolumn{2}{|c|}{$\begin{array}{l}\text { At official } \\
\text { exchange rate }\end{array}$} & \multicolumn{2}{|c|}{$\begin{array}{l}\text { At purchasing } \\
\text { power value }\end{array}$} & & & & \\
\hline & Dollars & Percent & Dollars & Percent & Dollars & Percent & $\begin{array}{l}\text { Billion } \\
\text { dollars }\end{array}$ & Percent & $\begin{array}{l}\text { Billion } \\
\text { dollars }\end{array}$ & Percent \\
\hline USA & 7010 & 100 & 4655 & 100 & 4655 & 100 & 1010 & 100 & 1010 & 100 \\
\hline USSR & - & - & 2115 & 45 & 2599 & 56 & 548 & 54 & 673 & 67 \\
\hline FRG & 4480 & 64 & 3270 & 70 & 2265 & 48 & 196.1 & 19 & 135.8 & 13 \\
\hline Japan & 3020 & 43 & 2235 & 48 & - & - & 242 & 24 & - & - \\
\hline
\end{tabular}

SOURCE: Statistical Yearbook of the USSR 1977.

TABLF 3 lndustrial productivity growth rates in major developed countries, 1963-1979.

\begin{tabular}{|c|c|c|c|c|c|c|}
\hline \multirow[b]{2}{*}{ Country } & \multicolumn{2}{|c|}{$\begin{array}{l}\text { Industrial } \\
\text { productivity } \\
\text { growth rate }\end{array}$} & \multirow{2}{*}{$\begin{array}{l}\text { Change in industrial } \\
\text { productivity } \\
\text { growth rate }\end{array}$} & \multirow{2}{*}{$\begin{array}{l}\text { Change in } \\
\text { output } \\
\text { growth rate }\end{array}$} & \multicolumn{2}{|c|}{$\begin{array}{l}\text { Industrial } \\
\text { productivity } \\
\text { grow th rate }\end{array}$} \\
\hline & $\begin{array}{l}1963- \\
1973\end{array}$ & $\begin{array}{l}1973- \\
1977\end{array}$ & & & 1978 & 1979 \\
\hline \multicolumn{7}{|c|}{ Planned economies } \\
\hline USSR & 5.6 & 4.8 & -0.8 & -1.4 & 3.5 & 2.4 \\
\hline Poland & 5.9 & 8.0 & 2.1 & 3.6 & 4.8 & 3.3 \\
\hline GDR & 5.3 & 5.3 & 0 & -0.3 & 4.2 & 4.2 \\
\hline Czechoslovakia & 5.4 & 5.6 & 0.2 & -0.7 & 4.1 & 2.9 \\
\hline Hungary & 4.6 & 6.3 & 1.7 & -0.2 & 5.9 & 4.5 \\
\hline Bulgaria & 6.7 & 6.7 & 0 & -4.3 & 6.4 & - \\
\hline Rumania & 7.0 & 7.8 & 0.8 & 0.1 & 6.8 & 6.4 \\
\hline \multicolumn{7}{|c|}{ Market economies } \\
\hline USA & 2.1 & 1.0 & -1.1 & -3.5 & 1.9 & 1.3 \\
\hline Japan & 8.9 & 3.7 & -5.2 & -9.5 & 8.8 & 9.6 \\
\hline IRG & 5.3 & 3.6 & -1.7 & -4.4 & 2.3 & 4.0 \\
\hline France & 5.2 & 4.0 & -1.2 & -3.4 & 5.0 & - \\
\hline UK & 3.9 & 1.3 & -2.6 & -3.6 & 3.4 & 3.1 \\
\hline Canada & 3.6 & 0.8 & -2.8 & -4.4 & 4.7 & 2.5 \\
\hline Italy & 5.6 & 0.8 & -4.8 & -4.1 & 3.0 & - \\
\hline
\end{tabular}

the economy of the FRG for the 27 years from 1951 through 1977. The average annual decline in productivity growth for this period was 0.2 percent.

According to a recent study (OECD Economic Outlook 1979), OECD countries are alarmed about their continuing decline in industrial productivity growth rates in tiie seventies. The productivity growth rates of the seven major CMEA countries are higher 


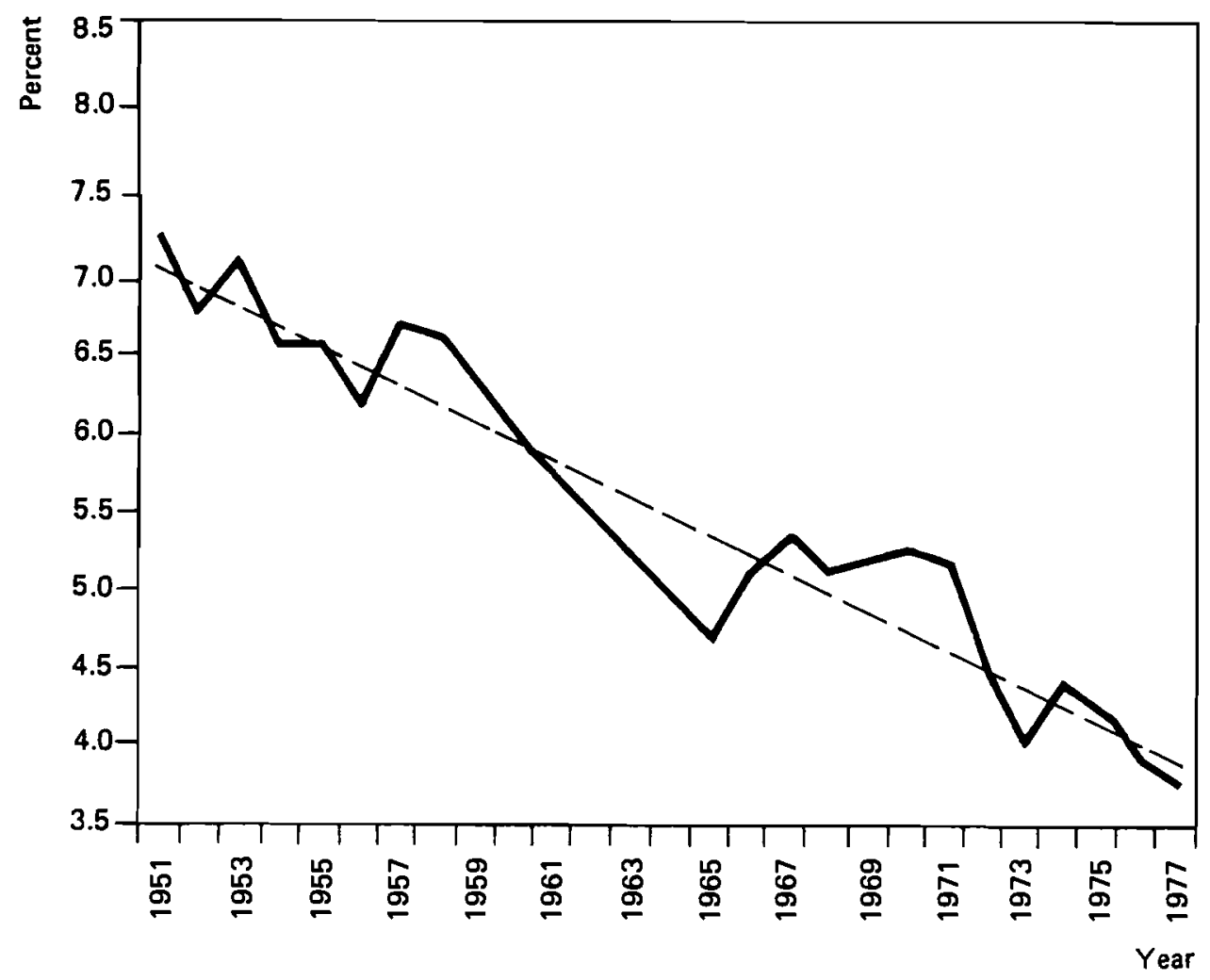

FIGURE 3 Productivity growth rates of the national economy of the FRG, 1951-1977 (moving averages of five years for gross domestic product in 1970 prices per working hour, all employees). Dotted line is trend line.

than are those of the seven major OECD countries. We do, however, find a negative or zero change in the productivity growth rates of the USSR, Czechoslovakia, and the GDR for the 1973-1977 period. Looking at data from several industries in Table 4, we note a decline in the productivity growth rates of nearly all industries in several countries. Poland, which had rapid industrialization during the reference period, is the single exception. Yet industrial productivity growth, which remains the main source of national welfare and the prime contributor to international competitiveness and equalization of gaps in resources, is important in both less developed and developed countries. Planned economies are seeking to reduce the productivity gap in order to be at the same level as market econonies. The time needed for equalization of productivity levels depends on the size of the gap, current growth rates, and future change in growth rates. Appendix A presents a method for calculating the time needed to equalize productivity levels in two countries.

The present decline in productivity growth rates, which is of course not conducive to equalizing productivity levels, cannot be explained simply by the levels of productivity reached. Instead, there must be a cause having a similar effect in all countries. The lack of basic innovations might be such a universal factor. The most important growth industries of the last 30 years have been chemicals, electrical engineering, automobiles, plastics, petroleum products, and aircraft. Now, however, we see a negative change in productivity growth even in these industries - which recently have not been compensated by new basic 
TABLE 4 Productivity growth rates of several industries in various countries $a$ (market and planned economies), $1963-1977$.

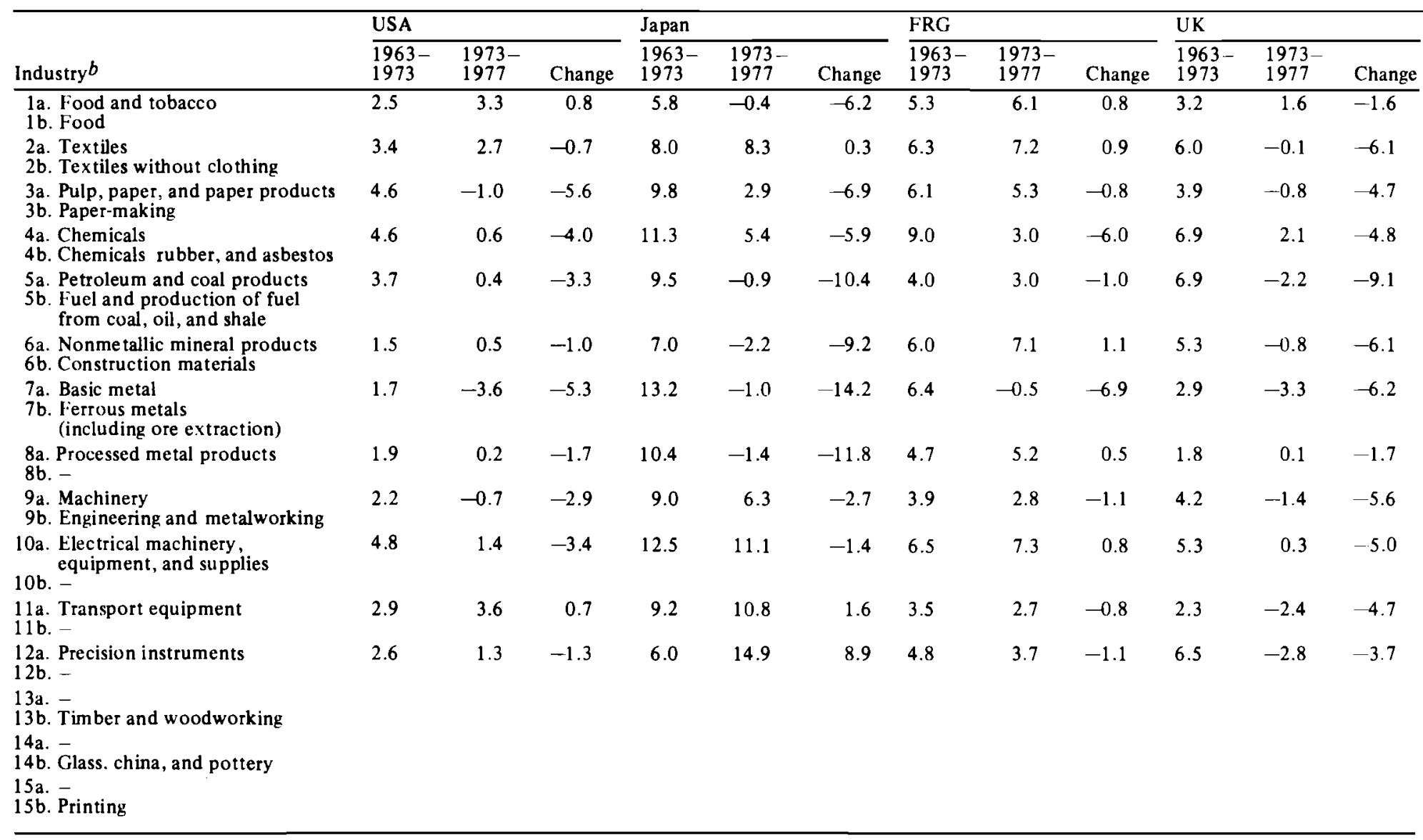




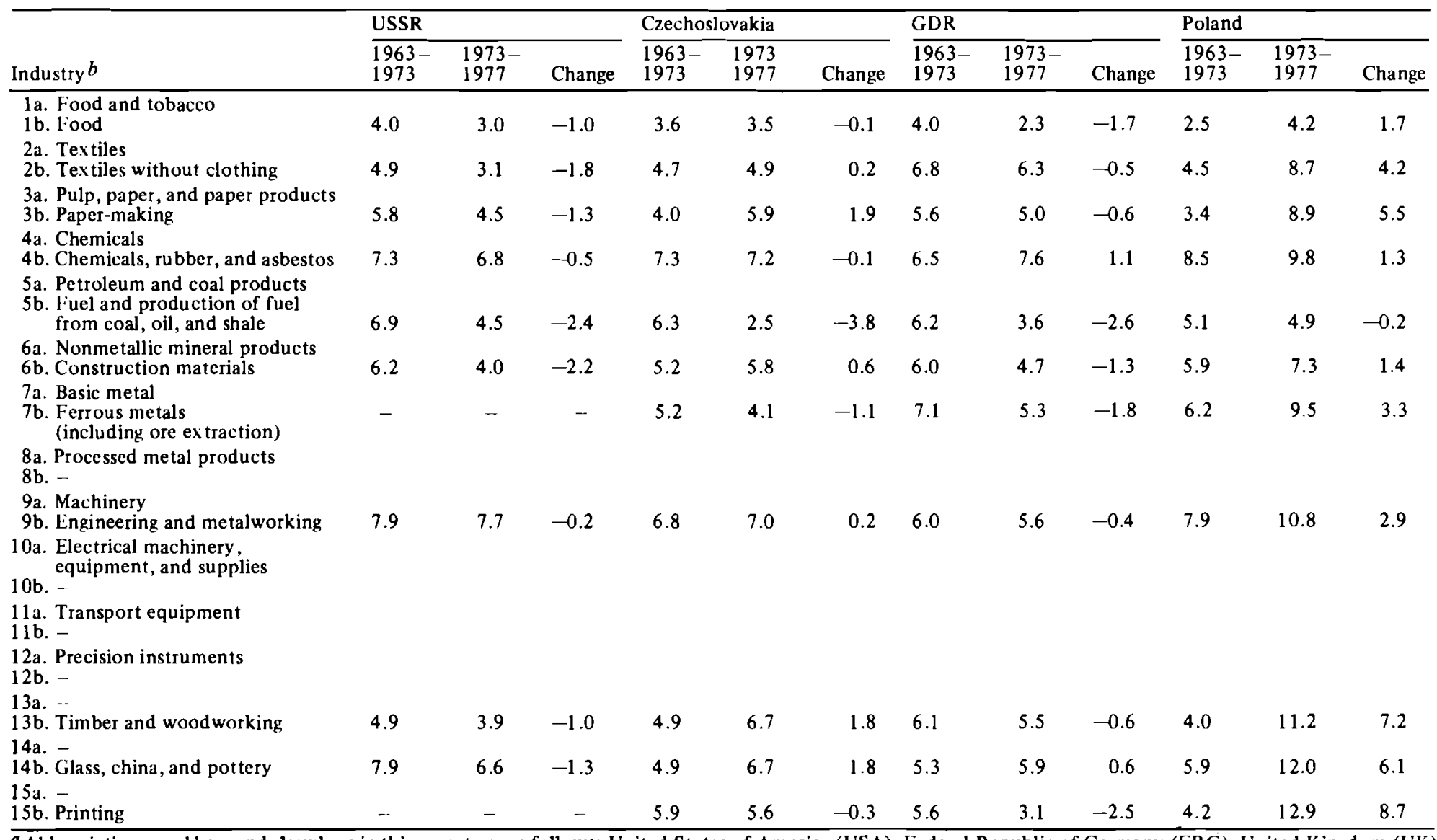

Abbreviations used here and elsewhere in this report are as follows: United States of America (USA), Federal Republic of Germany (FRG), United Kingdom (UK), Union of Soviet Socialist Republics (USSR), and German Democratic Republic (GDR).

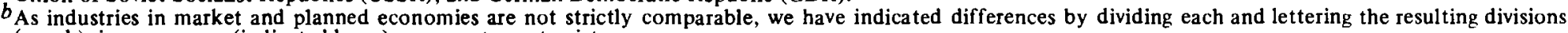

(a or b); in some cases (indicated by $\cdots$, no counterpart exists.

SOURCE: Adapted from OECD Economic Outlook 1979 and statistical yearbooks of CMEA countries. 
innovations. How, then, might the lack of basic innovations explain the decline in productivity growth rates?

Two tendencies have a great effect on efficiency. First, an increasing capital coefficient leads toward improvement of a given technological system. Essential changes are of no interest if they are linked with large losses in capital funds, and the capital coefficient is a general measure for many specific problems at the level of the firm. Table 5 shows some of the problems arising at this level (in marketing, production, research and development, management, and social consequences) during the transition from a policy of improvement (that is, changes of lower order) to one of basic technological change. Second, many

TABLE 5 Implications of policy of improvement or of basic technological change at the level of the firm.

\begin{tabular}{|c|c|c|}
\hline \multirow[b]{2}{*}{ Factor } & \multicolumn{2}{|l|}{ Implications of policy } \\
\hline & Improvement & Basic technological change \\
\hline \multirow[t]{4}{*}{ Marketing } & $\begin{array}{l}\text { Demand relatively low, well } \\
\text { known, and predictable }\end{array}$ & $\begin{array}{l}\text { Demand high and relatively } \\
\text { unpredictable }\end{array}$ \\
\hline & Risk of failure low & Risk of failure ligh \\
\hline & Acceptance rapid & Acceptance slow initially \\
\hline & $\begin{array}{l}\text { Well-known marketing channels } \\
\text { used }\end{array}$ & $\begin{array}{l}\text { Creation of a new marketing system } \\
\text { necessary }\end{array}$ \\
\hline \multirow[t]{3}{*}{ Production } & $\begin{array}{l}\text { Capacities of existing labor, skills, } \\
\text { and cooperation used maximally }\end{array}$ & $\begin{array}{l}\text { Capacities of existing labor, skills, } \\
\text { and cooperation becoming obsolete }\end{array}$ \\
\hline & $\begin{array}{l}\text { Learning processes and designs } \\
\text { streamlined }\end{array}$ & Learning processes interrupted \\
\hline & $\begin{array}{l}\text { Risk in quality and process } \\
\text { planning high }\end{array}$ & $\begin{array}{l}\text { Problems in quality, costs, and } \\
\text { effects new and unanticipated }\end{array}$ \\
\hline \multirow[t]{3}{*}{ Research and development } & $\begin{array}{l}\text { Existing research and development } \\
\text { potential used }\end{array}$ & Advanced research potential needed \\
\hline & Basic research not needed & $\begin{array}{l}\text { New research fields and disciplines } \\
\text { needed }\end{array}$ \\
\hline & $\begin{array}{l}\text { Rescarch and development risk } \\
\text { relatively predictable }\end{array}$ & Research and development risk high \\
\hline Management & $\begin{array}{l}\text { lamiliar management systems } \\
\text { uscd and given organizational } \\
\text { solutions adapted }\end{array}$ & $\begin{array}{l}\text { New inanagement skills, methods, } \\
\text { and organizational solutions needed } \\
\text { Complexity increased }\end{array}$ \\
\hline Social consequences & $\begin{array}{l}\text { Unpredictable problems rare or } \\
\text { nonexistent }\end{array}$ & $\begin{array}{l}\text { Legul and social acceptance } \\
\text { unpredictable }\end{array}$ \\
\hline
\end{tabular}

firms show a strong tendency to follow a policy of improvement. Figure 4 and Table 6 show this development over a 20 -year period in the USA, where the number and percentage of radical breakthroughs are declining rapidly. The same situation can be identified in other countries.

On the other hand, the situation changes according to the industry or group of products. Over the 1953-1973 period, the number of major innovations in electrical equipment 


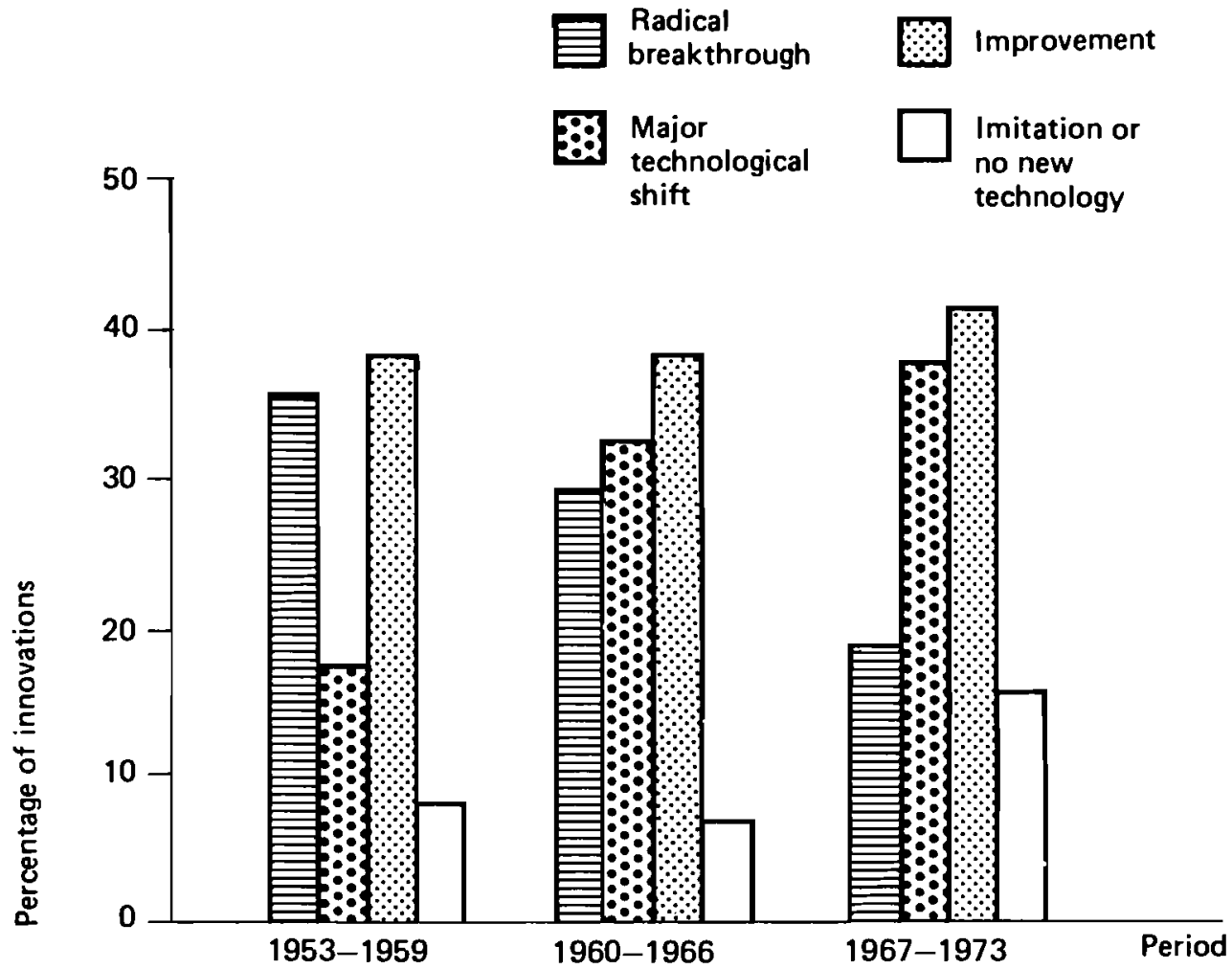

FIGURE 4 Estimated radicalness of major US innovations, 1953-1973. Source: US National Science Board 1977.

TABLE 6 Estimated radicalness of major US innovations by percent distribution and number of innovations, $1953-1973$.

\begin{tabular}{|c|c|c|c|c|}
\hline \multirow[b]{2}{*}{ Radicalness } & \multicolumn{4}{|l|}{ Period } \\
\hline & $1953-1973$ & $1953-1959$ & $1960-1966$ & $1967-1973$ \\
\hline & \multicolumn{4}{|c|}{ Percentage distribution } \\
\hline Radical breakthrough & 26 & 36 & 26 & 16 \\
\hline Major technological shift & 28 & 17 & 31 & 35 \\
\hline Improvement & 38 & 39 & 37 & 40 \\
\hline Imitation or no new technology & 8 & 8 & 6 & 10 \\
\hline \multirow[t]{2}{*}{ Total $a$} & 100 & 100 & 100 & 100 \\
\hline & \multicolumn{4}{|c|}{ Number of innovations } \\
\hline Radical breakthrough & 64 & 27 & 24 & 13 \\
\hline Major technological shift & 70 & 13 & 29 & 28 \\
\hline Improvement & 96 & 29 & 35 & 32 \\
\hline Imitation or no new technology & 20 & 6 & 6 & 8 \\
\hline Total $a$ & 250 & 75 & 94 & 81 \\
\hline
\end{tabular}

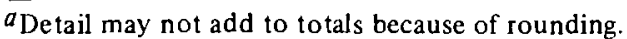

SOURCE: Adapted from US National Science Board 1977. 
and communications was significantly higher than that in traditional textiles or paper production. Principal technical solutions used in washing machines, refrigerators, textile machines, batteries, electric tools, combustion engines, and transport machines are, on the average, more than 25 years old, while those used in radio components, electronic calculators, and watches are generally less than 10 years old.

For a more comprehensive explanation of the productivity dilemma, we obviously must study the long-term tendencies shown by economic mechanisms and resource utilization. As we plan to investigate these tendencies in a future report, we shall not pursue the topic further here.

Over time, the productivity growth rates of various industries (see Table 4) show a developmental pattem illustrated by efficiency development in the lighting industry (see Fig. 5). The incandescent lamp, a basic innovation of the last century, reached an absolute

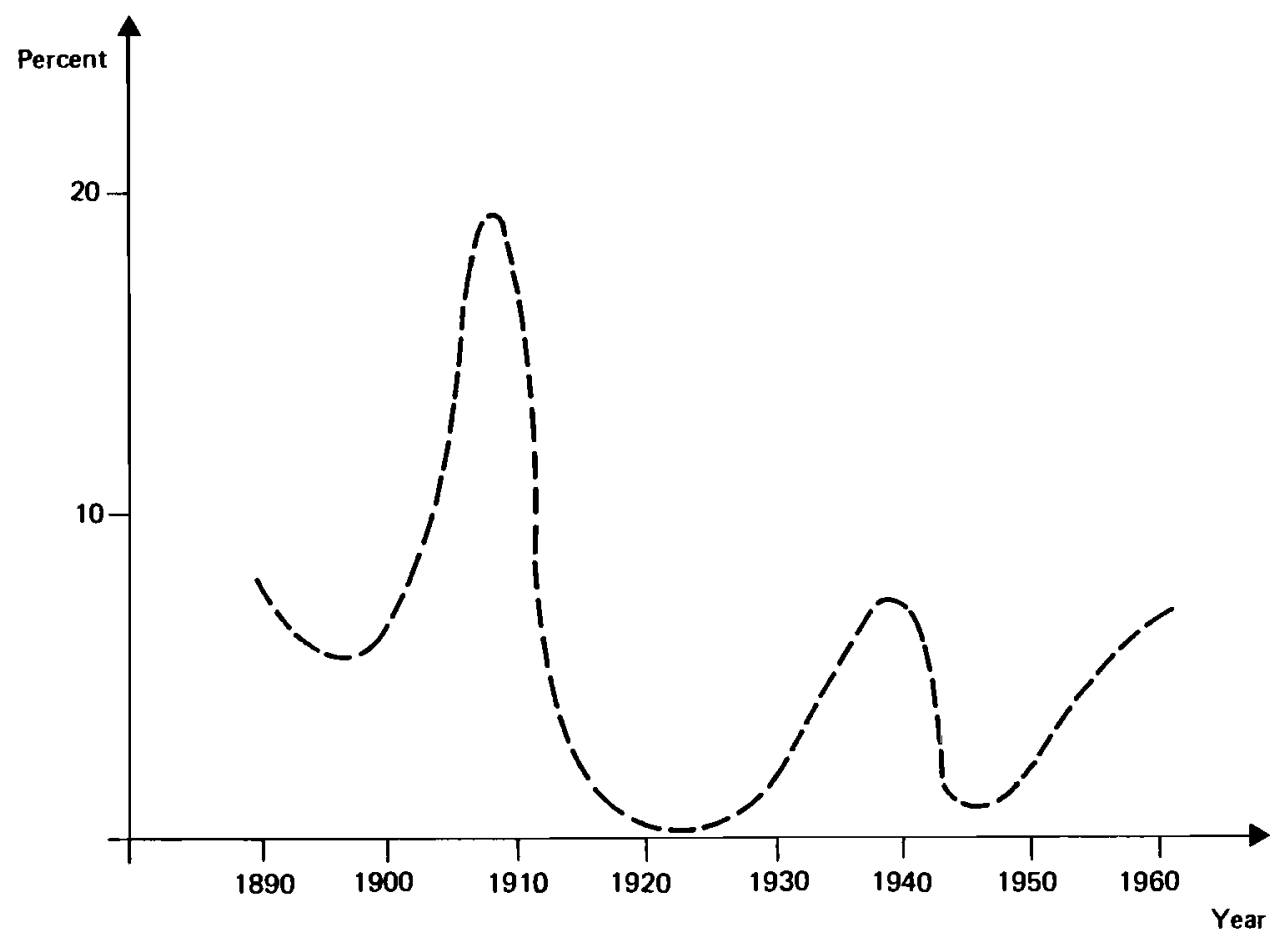

FIGURE 5 Annual percentage change in efficiency development in the lighting industry (incandescent lamps) in Imh (lumen hours of useful life) per dollar costs, 1890-1960.

peak in productivity growth rates before the First World War during a stage of rapid growth that can also be found in the developmental pattern of other industries. Such a natural trajectory is of course not only determined by the characteristics of the specific innovation process; it is also influenced strongly by the environment affecting the innovation and by interaction with other industries (see Haustein 1979). To include these factors in our consideration, we use the concept of relative efficiency, which was developed to meet the needs of planned economies (see Haustein 1976). 


\subsection{Relative Efficiency}

The indicators of efficiency in a given production system cannot tell us whether the system is using allocated resources because of requirements imposed by the economic system as a whole. We should therefore compare these indicators with those of the next higher system (for example, a sector of industry) or with those of the entire industry.

Efficiency is the relation of output $O$ and input $J$ over time $t$ :

$$
e(t)=O(t) / J(t)
$$

The efficiency of an innovating system (dynamic efficiency) is

$$
e_{i}(t)=O_{i}(t) / J_{i}(t)
$$

The efficiency of a higher system is

$$
e_{s}(t)=O_{s}(t) / J_{s}(t)
$$

The relative efficiency of an innovating system is therefore

$$
e^{*}(t)=e_{i}(t) / e_{s}(t)
$$

However, the efficiency of a higher system is

$$
e_{s}(t)=\frac{\sum_{i=1}^{n} e_{i}(t) p_{i}}{\sum_{i=1}^{n} e_{i}(t)}
$$

where

$e_{i}(t)$ is the efficiency of production system $i$, where $i=1,2, \ldots, n$ $p_{i}$ is the production share of the system $i$

and

$$
\sum_{i=1}^{n} p_{i}=1
$$

Clearly, then, the efficiency of the next higher system depends not only on the efficiency of the innovating systems $i=1,2, \ldots, m$ but also on the efficiency of the noninnovating systems $m+1, m+2, \ldots, n$ and on the subsequent weights of those production systems. Efficiency of the innovating system that is high in comparison to that of former times may actually be a low relative efficiency if the next higher system has improved its average efficiency conside rably.

Absolute or average efficiency of an innovating system is cyclical, with five stages in the cycle: take-off, rapid growth, maturation, saturation, and decline. Table 7 shows the 
TABLE, 7 Characteristics by stage of the efficiency cycle of an innovating system.

\begin{tabular}{|c|c|c|c|c|c|c|}
\hline \multirow[b]{2}{*}{ No. } & \multirow[b]{2}{*}{ Charac teristic } & \multicolumn{5}{|l|}{ Stage } \\
\hline & & Take-off & Rapid growth & Maturation & Saturation & Decline \\
\hline 1 & Example & Solar energy & Microelectronics & Synthetic fibers & Shoemaking & Ship building \\
\hline 2 & Product-related change & Very high & High & Medium & Low & Very low \\
\hline 3 & Process-related change & Low & Medium & Higl & Medium & Low \\
\hline 4 & $\begin{array}{l}\text { Number of technolog- } \\
\text { ical opportunities }\end{array}$ & Very high & High & Medium & Low & Low \\
\hline 5 & $\begin{array}{l}\text { Dominant kind of } \\
\text { innovation }\end{array}$ & Basic & $\begin{array}{l}\text { Improvement- } \\
\text { related }\end{array}$ & $\begin{array}{l}\text { Improvement- } \\
\text { related }\end{array}$ & $\begin{array}{l}\text { Improvement- } \\
\text { related }\end{array}$ & Pseudo \\
\hline 6 & $\begin{array}{l}\text { Dominant kind of } \\
\text { change in production } \\
\text { units }\end{array}$ & New establishments & Enlargements & Total modernization & Rationalization & Rationalization \\
\hline 7 & Teehnological policy & Push & Push and compensiation & Compensation & Compensation & Compensation \\
\hline 8 & Patent activity & High & Very high & Medium & Low & Very low \\
\hline 9 & Economic organization & Very flexible & $\begin{array}{l}\text { Flexible; increasing } \\
\text { number of firms }\end{array}$ & $\begin{array}{l}\text { Increasing vertical } \\
\text { integration; high } \\
\text { economics of scale }\end{array}$ & $\begin{array}{l}\text { Increasing diversifica- } \\
\text { tion; declining number } \\
\text { of firms }\end{array}$ & $\begin{array}{l}\text { Declining number of } \\
\text { firms }\end{array}$ \\
\hline 10 & Competitive situation & $\begin{array}{l}\text { Performance of } \\
\text { product dominant }\end{array}$ & $\begin{array}{l}\text { Performance of } \\
\text { product dominant }\end{array}$ & Quality dominant & Price dominant & Outsider as innovator \\
\hline 11 & Export policy & Low export activity & High share of exports & $\begin{array}{l}\text { Declining share of } \\
\text { exports }\end{array}$ & $\begin{array}{l}\text { Production moved } \\
\text { abroad }\end{array}$ & $\begin{array}{l}\text { Production moved } \\
\text { abroad }\end{array}$ \\
\hline 12 & Labor demand & Rapidly increasing & lncreasing & Static & Decreasing & Decreasing \\
\hline 13 & Capital intensity & Low & High & Higl & Very high & High \\
\hline 14 & $\begin{array}{l}\text { Personnel } \\
\text { requirements }\end{array}$ & $\begin{array}{l}\text { Scientific and } \\
\text { engineering expertise }\end{array}$ & Management skills & $\begin{array}{l}\text { Unskilled and } \\
\text { seniskilled labor }\end{array}$ & More skilled labor & $\begin{array}{l}\text { Drastic reduction in } \\
\text { employees required }\end{array}$ \\
\hline 15 & Management & $\begin{array}{l}\text { Informally organized } \\
\text { and prone to take risks }\end{array}$ & $\begin{array}{l}\text { Dominated by } \\
\text { entrepreneurs }\end{array}$ & $\begin{array}{l}\text { Dominated by } \\
\text { experienced organizers }\end{array}$ & Bureaucratic & $\begin{array}{l}\text { Marked by change in } \\
\text { upper levels }\end{array}$ \\
\hline 16 & Societal need & Very high & High & Medium & Medium & Low \\
\hline 17 & Deniand & Low & High & Very high & Medium & Low \\
\hline 18 & $\begin{array}{l}\text { Absolute efficiency } \\
\text { (growth rates) }\end{array}$ & Very low & Very high & High & Medium & Low \\
\hline 19 & Allocation of resources & Low & Medium & High & Very high & Medium \\
\hline 20 & Total benefits & Very low & Medium & High & Very high & Low \\
\hline
\end{tabular}


cycle's characteristics, which we derived from case studies. Number 1 gives examples of industries in various stages, while numbers $2-8$ describe technological features. The tradeoffs among these indicators are significant for technological policy in an industry. For example, there is no congruence between product-related change (2) and process-related change (3), especially in the first three stages. We need to determine whether the decrease in efficiency growth rates of product-related change from take-off through decline can be compensated by the efficiency growth rates of process-related change, and if so, for how long. Numbers 9-17 describe the cycle in economic terms. Managerial requirements obviously differ over the five stages. Fluctuations in efficiency often result from managers' slow or inappropriate reaction to changes. Numbers $18-20$ show a more aggregated tradeoff. Growth rates of absolute efficiency (18) are normally highest during rapid growth, but the absolute sum of benefits (20) is normally highest during saturation; thus managers are often unaware of the transition threatening to lead to the last stage, decline.

Table 8 reflects the developmental patterns of leading industries in the FRG, where structural change resulted from a number of basic innovations used after the Second World War. However, we should not forget that an innovation is always the fusion of economically relevant demand and technical feasibility.

TABLE 8 Share of innovative industries (in percent) in the net production of the manufacturing and mining industries in the FRG, 1950-1977.

\begin{tabular}{lcccrrrr}
\hline & \multicolumn{7}{l}{$\begin{array}{l}\text { Share in net production of manufacturing and mining industries in the } \\
\text { FRG (in percent) }\end{array}$} \\
\cline { 2 - 8 } Industry & 1950 & 1955 & 1960 & 1965 & 1970 & 1975 & 1977 \\
\hline Petrochemicals & 0.88 & 1.30 & 2.22 & 3.33 & 3.80 & 3.56 & 3.47 \\
Plastics & 0.22 & 0.40 & 0.73 & 1.20 & 1.73 & 2.34 & 2.57 \\
Aircraft engineering & - & - & 0.15 & 0.30 & 0.45 & 0.45 & 0.40 \\
Chemicals & 7.05 & 7.06 & 7.08 & 8.45 & 10.51 & 11.77 & 12.23 \\
Electronics & 4.84 & 6.84 & 8.19 & 8.93 & 9.96 & 11.06 & 11.72 \\
Automobile engineering & 2.94 & 4.53 & 6.04 & 6.64 & 7.49 & 7.32 & 8.13 \\
$\quad$ Total & 15.93 & 20.13 & 24.41 & 28.85 & 33.94 & 36.50 & 38.52 \\
\hline
\end{tabular}

SOURCE: Adap ted from Krengel et al. 1973, I975, 1978.

The higher efficiency of an entire industry no doubt accounts for rapid development in the industry'sinnovative sectors, but data also indicate a diminishing rate of relative efficiency (see Krengel et al. 1973, 1975, 1978). The growth rate of labor productivity in the innovative sectors in comparison to that in manufacturing industry as a whole was significantly higher from 1950 to 1955 than from 1973 to 1977 . During the 1950-1955 time span, the growth rate of labor productivity in the petrochemical industry was 2.6 percent higher; in plastics, 2.0 percent higher; in aircraft engineering, 11.4 percent higher; in chemicals, 1.4 percent higher; in electrical engineering, 1.4 percent higher; and in automobile engineering, 3.1 percent higher than in manufacturing industry as a whole. During the 1973-1977 time span, the growth rate of this factor was significantly lower: in the mineral industry, 1.9 percent lower; in plastics, 1.5 percent lower; in chemicals, 0.46 percent lower; in electrical engineering, 1.7 percent lower; and in automobile engineering, 1.6 percent lower than in manufacturing industry as a whole. 
We can draw the following conclusions from these statistics and from our case studies:

1. A period of high dynamic (as opposed to average) efficiency follows the takeoff stage.

2. Through better use of basic innovations the production process becomes increasingly capital-intensive and decreasingly labor-intensive. A diminishing rate of rela tive efficiency results, with a tendency for production units that have adopted an innovation to lose, after some time, the advantages of dynamic efficiency and to approach the average efficiency of the entire industry.

3. In the future, dynamic efficiency will depend largely on a country's ability to exploit new fields of innovation.

4. The main concern of a country in its innovation policy should be to have the optimal combination of business activities in various stages of the innovation cycle. Countries, industries, or firms concerned primarily with activities of the take-off stage may find themselves lacking sufficient economic resources to exploit these activities through improvement-related innovations. Countries, industries, or firms dominated by activities of the maturation stage, such as limitation and improvement of given technologies, incremental innovation, diversification of products, exploitation of scale economy, extension of vertical integration, and automation of production processes, will lose their advantage with respect to dynamic efficiency and experience stagnation.

To find the proper mixture of business activities in various stages of the innovation cycle, we need information about the characteristics of innovations. Distinctions that are important on the level of the production unit may be unimportant or impractical on a higher level. On the macroeconomic level, we think that it is important to distinguish between basic, improvement-related, and pseudo innovations. Basic innovations create new potential for efficiency and open new fields and directions for economic activities. Improvement-related innovations, many of which are incremental innovations, absorb this potential for efficiency by improving the given system and bringing it into balance. Improvement-related innovations become pseudo innovations at the point where they are unable to achieve higher efficiency in production.

A crucial task to improve innovation policy at the national and company levels is to provide information about future fields of innovation, which are dependent on various factors that fall into three categories:

- Urgency of demand for the innovation

- Existence of scientific and technological solutions to meet unsatisfied or latent demand

- Existence of a social environment that allows the fusion of demand-related factors and scientific-technological feasibilities

From the perspective of our current knowledge, for example, we can say that in the next two decades nations will achieve high dynamic efficiency, enabling innovation in the follow. ing fields:

- The electronics complex (especially applied microelectronics), which will make further development in automation possible 
- The energy and environment complex

- Biochemistry and the food production complex

Technologies able to provide new organizational solutions to solve communication, traffic, urban, health, and recreation problems

Successful innovators will probably be those able to respond effectively in these fields of innovation. Once the right direction is chosen, success depends on managing the factors that influence innovative activities.

\section{FACTORS INFLUENCING INNOVATIVE ACTIVITIES: AN ANALYTIC APPROACH}

\subsection{A Model of the Innovation Process}

\subsubsection{Innovation vs. Invention}

Innovation, a well-known term since the days of Schumpeter, should not be confused with invention (see Schumpeter 1952). Innovation includes the activities, not only of research and development, but also of technical realization and commercialization. In looking at the great number of studies and books on innovation that have been published, we noted first, the microeconomic approach used in most studies and second, the common view of innovation as a single process, a single technological change (in the narrow sense of the word technological). We think that innovation must be treated differently. The history of technology provides many examples where single important technical solutions had no socioeconomic impact (see Haustein 1974). We do not consider such solutions to be innovations.

The steamboat Great Eastem, for example, was a fundamentally new solution in the mid-nineteenth century. Its motive power was 100 times stronger than that of customary ships, while its tonnage was up to 7 times greater. Such a ship was, however, inappropriate at that time, as ports and service facilities were not able to accommodate it. After several years, the shipping trade firm that owned the steamboat, unable to withstand its economic consequences, went into bankruptcy (see Henriot 1955).

As a second example, many inventions in electrical engineering were well known a century ago. The 1883 exhibition of electrical products in Vienna included, for instance, electric water heaters, hearths, cushions, and motors, but there was no application for such devices in the existing complexes of needs and resources. Only one invention (the incandescent lamp) completely changed the existing system of demand (that for lighting). The Berlin power station was built in 1885 , and until 1900 electrical demand was primarily for lighting. Electric lighting was accepted as a basic innovation for two reasons. First, a rapid increase in demand could be established in this field. Electrical illumination of the Munich opera, for instance, had a striking effect. Second, Edison, the pioneer in this area, was not only a great inventor but also a good systems engineer and entrepreneur. He built a complete system, from production and distribution to usage, for satisfying the demand for lighting. He initially set the price for one lamp at $\$ 0.40$, but costs were higher $-\$ 1.25$. After three years he was able to reduce costs to $\$ 0.37$ and to obtain large profits from an explosion in demand.

These examples suggest the difference between technological change in a narrow sense and the innovation process. Innovation always causes a change in the technological 
system, with a great impact on the socioeconomic system or subsystem affected. Such subsystems are

- Complexes and subcomplexes of needs or demand (e.g., demand for lighting)

- Complexes and subcomplexes of resources (e.g., sources of energy)

- Processing cycles from primary production stages to final consumption (e.g., the wood cycle from forestry to the use of furniture)

(We also differentiate between basic and improvement-related innovations from this standpoint in Section 2.5.)

\subsubsection{Other Terms}

After many years of conceptual confusion and dissension about the proper definition of the range of research in studies of technological innovations, we have learned that only a comprehensive and complex approach provides useful results. The need for such an approach provides us with a starting point for describing our conceptual model for analyzing the process of technological innovation. Figure 6 provides a context for the terms used. According to the procedure prevailing in innovation research, we define innovation, for the time being, as the total process of research, development, and application of a technology; this initial working definition for a limited analy tical purpose omits exploitation, the fourth innovative activity shown in Fig. 6. By technology, we mean the knowledge of the properties and applicability of a technique. $\dagger$

A technology may be related to a product or to a production process. Each of the innovative activities may be divided into two stages, producing the analytical sequence of innova tive activities shown in Fig. 6: basic research; applied research; technological development; commercial development; application in production (of a product or of the hardware or software of a process); and application in consumption (use of a product or process).

These distinctions, which are made for analy tical purposes only, are not intended to show a necessary progression over time. There may be breaks and lags, and several activities related to the same technology may be performed simultaneously. In particular, research and development - even basic research - may be carried on after a technology has been applied for many years. In pharmacy, for example, the effectiveness of new products is often recognized without certain knowledge of the way in which the products work. A product or production process long since applied may thus be the subject of investigation.

There are two ways to show the innovation process over time. For theoretical purposes, we can use a spiraling model, where time is the axis within the spiral and the spiral consists of a carousel of the six previously mentioned innovative activities. For empirical studies, however, another approach seems more adequate. The situation of a technology and an innovator (see Section 2.1.3) in the case of exploring and developing a new technology is completely different from that in the case of realizing and improving an existing, previously applied technology. Thus we supplement research, development, and application by a fourth stage, exploitation, to take into account innovative activities that may be carried on after a technology is initially applied. We chose this term to reflect the innovator's

\footnotetext{
+ This distinction, which is in keeping with the historically based custom of German science, is made only for clarification; for the purpose of this report, it is sufficient to use "technology" in its "isual broader sense.
} 


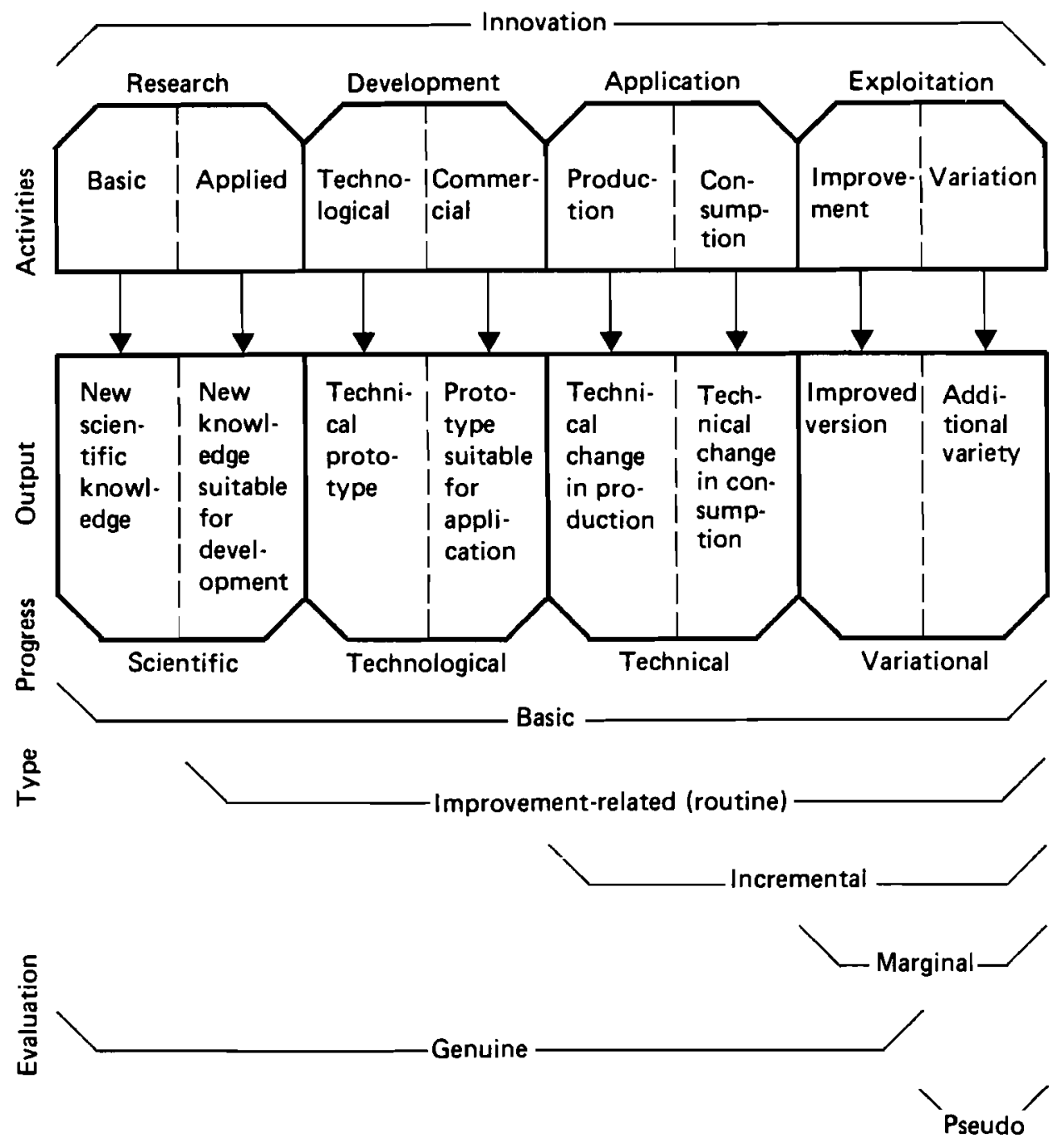

Flow of the innovation process

FIGURE 6 The innovation process.

propensity to make full use of the additional opportunities offered by a technology that has already been applied. The exploitation stage is also divided into two activities: improvement and variation of the technology.

Figure 6 shows that the various innovative activities result in different kinds of output: basic research, in new scientific knowledge; applied research, in new knowledge suitable for development; technological development, in a technical prototype;commercial development, in a prototype suitable for application; production, in a technical change in production; consumption, in a technical change in consumption (use); improvement, in an improved version of the technology; and variation, in additional variety. 
The innovation process results in four different kinds of progress: scientific progress from research, technological progress from development, technical progress (in the technological but not necessarily in the economic sense) from application, and variational progress from exploitation. In this context, progress is a strictly conceptual term, not an assessment of the activities' results. New knowledge, a new prototype, a technical change, and additional variety of the technology are new possibilities that increase the opportunities to choose among alternatives, including those offered by existing technologies. These new possibilities are therefore kinds of progress.

We do not believe that a typology of innovation can be derived solely on the basis of a single innovation process. The decisive criterion for classifying innovations as basic, improvement-related, incremental, or marginal is related to the interaction between innovation processes and the environment. On the other hand, the major types of innovation can also be shown by their location within the scheme.

Bearing in mind that innovation research began by investigating activities related to the problems and benefits of dealing with something technologically new, we call such activities genuine innovations only when they result at least in a technically improved version of the technology under consideration. In contrast, we term activities resulting only in additional variety of the technology pseudo innovations. Genuine innovations are the real subject of innovation research. However, attempting to trace the influence of the life cycle of a technology on the efficiency of the system of which the technology is a part of course necessitates looking at the total process of innovation (i.e., the life cycle the innovation has passed through until that time), which includes activities involving both genuine and pseudo innovations.

Having dealt with the various kinds of innovative activities and types of innovation, we now tum to the innovation system and those involved in innovative activities.

\subsubsection{The Innovation System}

As we feel that a microeconomic approach to innovation or a definition oriented to a single process is not sufficiently operational and prefer to view innovation as a change in the technological system with a great impact on the given economic system or subsystem, we have devised a scheme with three levels representing subsystems of the innovation system. The first is the innovator, the person or group carrying on innovative activities; the second, the organization within which the innovator acts; and the third, the social, economic, and political environment of the organization. The term environment is of course general and requires explanation. In planned or market economies there is no simple "selection environment" in the biological sense of the term as used by Nelson and Winter (1977). An economic environment is hierarchically structured and consists of at least two levels, microeconomic and macroeconomic, which have their own laws and regularities. The levels must be linked, not by extending the laws of one to the other, but by studying their interaction. The economic environment surrounding innovations is an operational or policyoriented environment that depends greatly on actions taken on the national level; this is true of both planned and market economies.

In a general sense we can define a system as a set of elements among which relationships exist. These relationships either may be of a structural nature, framing the system, or may actually take shape in the system; the latter are called process-related variables. Combining our concept of three levels with this definition of a system, we arrive at the matrix of nine cells shown in Table 9.

In economic terms, the innovation process is a production process transforming input (production factors) through innovative activities into output (progress). This concept 
TABLE 9 Components of the innovation system.

\begin{tabular}{llll}
\hline & \multicolumn{2}{l}{ Variables related to } & \\
\cline { 2 - 4 } Level & Elements & Structure & Process \\
\hline Innovator & a. Input/output & b. Interaction among innovators & Innovative activities $a$ \\
Organization & c. Resources & d. Organizational dimensions & e. Organizational measures \\
Environment & f. Resources & g. Environmental dimensions & h. Environmental measures \\
\hline
\end{tabular}

$a$ Variables a $\mathrm{h}$ are factors influencing innovative activities.

connects the components of the innovation system, shown in Table 9, with the flow of the innovation process, shown in Fig. 6.

The inputs into the innovation process (such production factors as labor, capital, materials, and technological know-how) are taken from an organization's resources; the organization in turn takes and receives input from its environment. The innovator's output (the various types of progress) augments the resources of the organization and of its environment. The transformation process (the shape of the production function) is determined by the quantity and quality of these resources and by the measures (steps, actions) taken by the organization and the environment to change the organization, which influences innovative activities. Furthermore, it is determined by the dimensions (general features) of the organization and of the environment, by the interaction among innovators, and, accordingly, by the efficacy of the process. Consequently, to draw conclusions about the efficiency of innovative activities in a given context (technology, time period, area), we must determine the factors influencing the activities and their efficacy with respect to those activities.

\subsection{Factors Influencing Innovative Activities}

\subsubsection{Groups of Factors}

Research has revealed a vast number of factors affecting the innovation process, especially those acting as barriers to innovative activities. It is not feasible to compile from the literature a list of factors that simultaneously is exhaustive but does not involve overlapping or double counting of terms. Therefore, we have established from our own experience a set of factors in which we have also tried to include the results of others' work; unfortunately, it is not possible to cite all the theoretical and empirical studies, the assumptions and findings of which we have included in our discussion. Our set of factors is not restricted to those factors that empirical studies have shown to influence concrete innovations. Instead, it contains as many factors as possible that might exert an influence.

We use Table 9 as a guideline for identifying and classifying the factors (a complete list of which appears in Appendix B). Following are the groups into which they may be distributed on the three levels of the innovation system.

I. Innovator

a. Input/output

a1. Input-related factors (necessary quantities and qualities of factors relating to production)

a2. Output-related factors (knowledge and utilization of the properties and possible applications of the technique) 
b. Interaction among innovators

b1. Interplay of functional roles (which must be fulfilled to accomplish innovative activities)

b2. Characteristics of innovators (persons playing these roles)

II. Organization

c. Resources (e.g., labor)

d. Organizational dimensions

d1. Relationships with the environment (e.g., recognition of clients' needs)

d2. Internal dimensions (e.g., system of goals)

e. Organizational measures

e1. Planning measures (e.g., selection of projects)

e2. Control measures (e.g., supervision of innovative activities)

III. Environment

f. Resources (e.g., capital equipment)

g. Environmental dimensions

g1. Economic sector (e.g., system of competition)

g2. Political sector (e.g., national goals)

g3. Social sector (e.g., system of social values)

h. Environmental measures

h1. Economic sector (e.g., cooperation with suppliers)

h2. Political sector (e.g., regulations)

h3. Social sector (e.g., public familiarity with the technology)

\subsubsection{Patterns Shown by the Factors}

The existence of these factors influences the performance of innovative activities; to a large extent, then, the factors govern the efficiency of innovative activities. The power of the factors to govern the efficiency of the activities (that is, their efficacy in influencing those activities) is likely to depend on certain circumstances, which we may determine by asking the following questions:

- Which factors influence which innovative activities?

- In doing so, which clearly inhibit and which clearly promote innovative activities? Which are of indistinct efficacy?

- With what strength or weight does a given factor influence innovative activities?

A given factor may, in a given situation, have the effect of a blockade, obstacle, facilitator, or incentive to innovative activities, according to a continuum of efficacy ranging from inhibiting to strongly promoting innovative activities. By combining these four possible effects with the systems approach developed thus far, we seek to gain a theoretical notion of the efficacy of the various kinds of factors before beginning empirical research, which must deal with an interwoven network of factors and activities in a particular case.

We can begin with three principles. First, we assume that the more a factor is present in a manner that is suitable (or is not present in a manner that is unsuitable) for innovative activities, the more it is likely that the factor will not stop but rather will promote these activities. In this context we shall differentiate in Section 2.3.1 among distress, slack, and 
excess of factors. $\dagger$ Second, the degree of likelihood of inhibiting or promoting innovative activities is higher on the level of the innovator than on those of the organization or environment because of the innovator's more direct and immediate influence. The farther the level is from the innovative activities, the greater is the distress to be compensated for and coped with. Third, and similarly, factors consisting of element- or process-related variables can influence innovative activities in a more direct and immediate manner than can factors related to structure. Table 10 illustrates these principles, but it can of course give only a hypothetical view of the prevailing efficacies.

TABLE 10 The prevailing efficacy of factors in the innovation system.

\begin{tabular}{|c|c|c|c|c|}
\hline \multirow[b]{3}{*}{ Level } & \multicolumn{4}{|l|}{ Factor } \\
\hline & \multirow{2}{*}{$\begin{array}{l}\text { Presence and } \\
\text { suitability }\end{array}$} & \multicolumn{3}{|l|}{ Related to } \\
\hline & & Elements & Structure & Process \\
\hline \multirow[t]{3}{*}{ Innovator } & Distress & Blockade & $\begin{array}{l}\text { Blockade } \\
\text { Obstacle }\end{array}$ & - \\
\hline & Slack & Facilitator & Facilitator & - \\
\hline & Excess & Incentive & Incentive & - \\
\hline \multirow[t]{3}{*}{ Organization } & Distress & Obstacle & Obstacle & $\begin{array}{l}\text { Blockade } \\
\text { Obstacle }\end{array}$ \\
\hline & Slack & & Facilitator & \\
\hline & Excess & Facilita tor & Facilitator & Incentive \\
\hline \multirow[t]{3}{*}{ Environment } & Distress & Obstacle & Obstacle & $\begin{array}{l}\text { Blockade } \\
\text { Obstacle }\end{array}$ \\
\hline & Slack & & Facilitator & \\
\hline & Excess & Facilitator & Facilitator & Incentive \\
\hline
\end{tabular}

Three types of change are responsible for altering the weight of a given factor during the innovation process:

A. Changes related to the stage of the innovation process

A1. Specific aspects of innovative activities (e.g., problems related only to research and development)

A2. Settlement or solution of the underlying problem (e.g., reduction of technological risk after a solution has been found)

A3. Shaping of the technology (e.g., insuring the success of market products)

B. Changes related to the expiration of time

B1. Exploitation of benefits (e.g., saturation of demand)

B2. Appearance of antagonists (e.g., emergence of competing firms or technologies)

B3. Altering of attitudes and values (e.g., boredom of those involved in innovative activities)

\footnotetext{
$\div$ Slack and distress situations were first used in innovation research by Knight (1967) in his model of the intra-firm innovation process.
} 
C. Changes compelled by "fate"

Accidental factors that are unforeseeable - that is, not definable from within the innovation system (e.g., changes in energy prices)

Our next problem is to combine these types of change with the set of factors and to apply the result to the innovative activities in order to determine the prevailing efficacy of particular factors during the innovation process. Obviously, changes compelled by fate cannot be considered because their efficacy is not predictable.

\subsection{Efficacy of Factors}

\subsubsection{The Concept behind Our Presentation}

In examining the varying inportance of the factors influencing innovative activities during the innovation process, we must concede some restrictions. First, we must concentrate on particularly striking relationships and omit those that seem to be of minor importance for the activity in question. Second, while empirical studies have provided us with a great deal of information about special features of the innovation process, no study covers all the influencing factors; for obvious reasons, no opportunity exists to carry out such a study adequately. Therefore, we are left with a mixture of evidence from empirical studies, results of theoretical reasoning, plausible arguments, and sheer truisms.

We think it best to start from the idea that innovative activities are encroachments on the existing state of life and therefore require a continuous impetus. Whether the "energy" for this impetus is provided depends on the presence and suitability of various factors. We may thus classify the factors according to the likelihood that they will act as blockades or as incentives to innovative activities, as mentioned previously. Neglecting, for the sake of brevity, the caution pointed out in Section 2.1.2 regarding the course of time and the progression of innovative activities, we may indicate the efficacy of a particular factor through the example shown in Fig. 7. The factor illustrated is presumably more likely to act as a

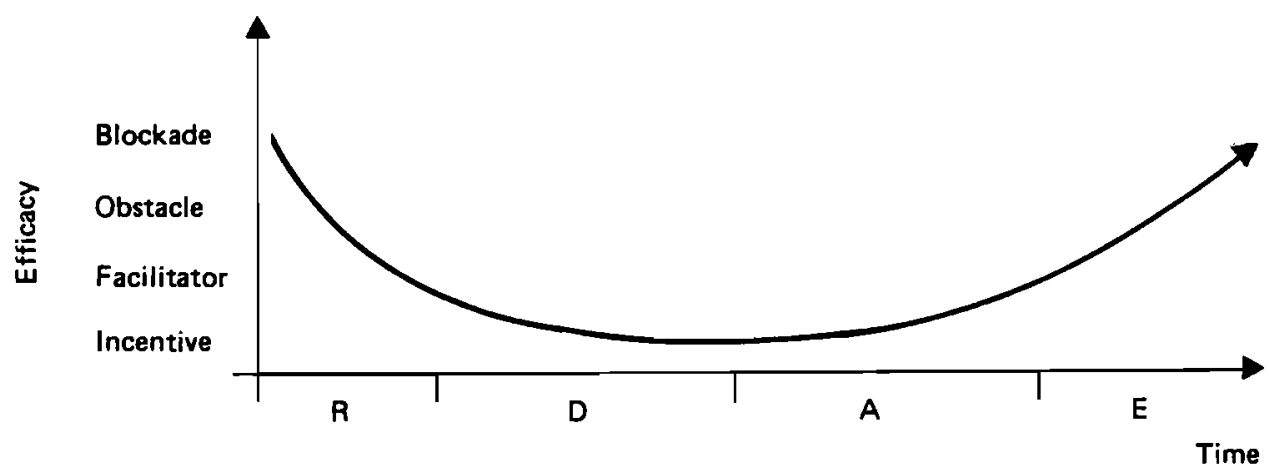

FIGURE 7 Efficacy of a factor influencing innovative activities, where $R$ is research, $D$ is development, $A$ is application, and $E$ is exploitation.

blockade early in the innovation process (overcoming this blockade would require a great deal of "energy"); then it promotes innovative activities for a time until finally blocking 
them once again. The factor is subject to a type of change that causes a sequence of distressslack-excess-slack-distress, resulting in the shape of the curve shown in Fig. 7; other types of change cause other shapes of curves for various factors. Figure 8 shows the curves appearing in Appendix B, where we have also used a wavy line to indicate cases where the sequence is not predictable.

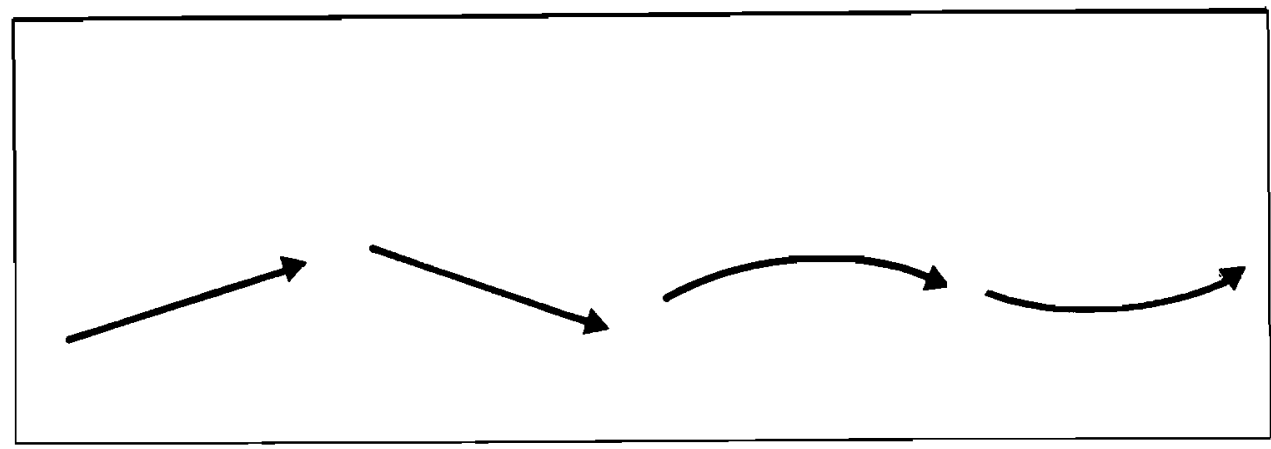

FIGURE 8 Curves representing efficacy of various factors influencing innovative activities.

We cannot determine which situation (distress, slack, excess) exists at a given level (innovator, organization, environment) of the innovation system without accurately knowing the circumstances of the subsystems at those levels. The most prudent way of tackling this problem seems to be to determine whether distress (for example) of a particular factor with regard to a given innovative activity and level of the innovation system might be a serious hindering factor. We are speculating, in other words, on the factor's efficacy in influencing innovative activities.

\subsubsection{Detailed Analysis}

Appendix B presents our hypotheses regarding the efficacy of factors influencing innovative activities during research (R), development (D), application (A), and exploitation (E). We treat the factors in the order presented in Section 2.2.1, give a short explanation of our hypotheses, and indicate (using the alphanumeric codes presented at the end of Section 2.2.2) the type of change most likely to predominate. Although it would be senseless to count the shapes of the various curves to find dominant characteristics, four features should not be overlooked.

First, the efficacy of most factors is determined by changes related to the stage of the innovation process: by settlement or solution of the underlying problem (A2) or, to a lesser extent, by occurrence of problems only during certain innovative activities (A1).

Second, comparison of the three levels (innovator, organization, environment) and types of variables (related to elements, structure, process) in the innovation system reveals on all three levels a succession of problems stemming from element-related variables (input/ output, resources). In the early stages of the innovation process, problems may arise from a lack of adequate labor, materials, facilities, and knowledge; later on, problems may arise from capital requirements and from the impact of the technology on the natural environment. With respect to element-related variables, then, there seems to be no general tendency for increasing or decreasing efficacy. 
Third, at the levels of the innovator and organization, the efficacy of structure-related variables tends to decrease over the course of innovative activities, whereas it tends to increase at the level of the environment, because the technology is increasingly implemented in the subsystems of the innovator and organization and ceases to be an extrinsic part of these subsystems. The technology may even become a part of the structure (e.g., goal system, long-term plan). At the level of the environment, however, the technology that is scaling up, requiring more and more resources, and having an increasing effect on the environment attracts more and more public attention, must overcome competition, and must be adjusted to the existing structure.

Fourth, the efficacy of process-related variables tends to decrease at the level of the organization and to increase at the level of the environment for reasons similar to those mentioned in the preceding paragraph. Measures that can be taken by the innovating organization are taken as early as possible, thus settling problems. In contrast, innovators and their organization must cope with measures stemming from the political, economic, and social sectors of their environment; these measures become increasingly relevant as the technology is exposed to the public.

Table 11 presents general conclusions drawn from analyzing factors influencing innovative activities at the level of the firm. These general tendencies are based on the hypotheses given in Appendix B and cannot, of course, be more than "macro-hypotheses"; if they are valid, the consequences are clear. One political implication, which we shall simply mention, is that because there is a sequence of tendencies related to the efficacy of factors influencing innovative activities, there is a corresponding sequence of priorities for policy-oriented measures designed to intensify incentives and to remove blockades to innovative activities; thus there must be many measures available to policy makers. The consequence of interest to us here, however, is the significance of the efficacy of various factors. The sequence of efficacies implies a sequence of incentives, facilitators, obstacles, and blockades in the innovation process.

\subsection{Control of Factors}

Our approach to determining the respective efficacy of various factors revealed a shifting of problems from the level of the innovator to that of the environment. This transition is easily understandable, as the purpose of any innovation process is to transfer the technology from the innovator's level to that of the environment. However, the innovator can control the factors influencing innovative activities to a much greater extent on his own level than on the level of the environment, where his ability to act on and react to factors is curtailed. Thus the likelihood that the innovator will determine the efficiency of the technology in question through purposeful methodological activities decreases.

If the current propensity is to concentrate increasingly on pseudo rather than genuine innovations, reflecting a stalemate in technology, perhaps it is because most of the factors influencing innovative activities exist on levels beyond the control of innovators. This consequence of the macro-hypotheses presented in Table 11 might explain the global decline in labor productivity: "pseudo" innovators must struggle more to increase efficiency than must "genuine" innovators, who can better overcome the factors acting as obstacles and blockades to their innovative activities. What types of innovation, then, can we distinguish from the standpoint of efficiency? 
TABLE 11 Tendencies related to the efficacy of factors influencing innovative activities at the level of the firm.

\begin{tabular}{|c|c|}
\hline \multirow[b]{2}{*}{ Levels } & Variables related to \\
\hline & Elements \\
\hline \multirow[t]{4}{*}{ Innovator } & a. Input/output \\
\hline & $\begin{array}{l}\text { Solving problems removes bar- } \\
\text { riers related to labor, materials, } \\
\text { facilities, and knowledge. }\end{array}$ \\
\hline & $\begin{array}{l}\text { Specific aspects of subprocesses } \\
\text { create barriers related to capital } \\
\text { and environment. }\end{array}$ \\
\hline & $\begin{array}{l}\text { Shaping the technology removes } \\
\text { barriers through the technology } \\
\text { itself. }\end{array}$ \\
\hline
\end{tabular}

Organization

Environment

General tendencies Resource-related problems shift

\section{c. Resources}

Solving problems removes barriers related to labor, materials, facilities, and knowledge.

Specific aspects of subprocesses create barriers related to capital and environment.

\section{f. Resources}

Solving problems removes barriers related to labor, materials, facilities, and knowledge.

Specific aspects of subprocesses create barriers related to capital and environment. from labor, materials, facilities, and knowledge to capital and environment.

Shaping the technology removes technological barriers (with the exception of increasing complex ity).
Structure

b. Interaction among innovators

Solving problems removes barriers through roles allocated and personal qualities demonstrated. Specific aspects of subprocesses govern the sequence of barriers related to role play of innovators.

d. Organizational dimensions Many dimensions cannot be classified.

Solving problems removes most barriers.

Barriers may arise from implementation of the technology and from the increasing rigidity of the established structure.

g. Environmental dimensions Many dimensions cannot be classified.

Specific aspects of subprocesses create barriers through public reaction, social acceptance, and the increasing relevance of the system of competitors.

Structure-related problems shift from internal to external areas.

Scaling up the technology attracts outside attention and widens the problem area.

Process

.

\section{e. Organizational measures} Solving problems and shaping the technology removes barriers that may be relevant at the beginning of the innovation process.

h. Environmental measures Solving problems removes some barriers.

Specific aspects of subprocesses and exploitation of benefits derived from the technology
create barriers related to compecreate barriers related to compe-
tition, social attitudes, and extension of the technology.

Influence shifts from that of the organization to that of the environment, which may react to extension of the technology. The organization's influence is increasingly diminished as work progresses.
General tendencies

Within the (innovator) sub system, most barriers are removed.

Barriers related to capital and environment may arise.

Within the (organization) subsystem, barriers related to labor and resources are removed.

Barriers related to capital and environment and to the rigidity of the established structure may of the
arise.

Within the (environment) subsystem, barriers related to competition, social values, and extension of the technology increase.

The development of problems governs the efficiency of innovative activities.

Problems shift from the level of the innovator to that of the environment.

Whereas realization removes 


\subsection{Classifying Innovations by Efficiency}

There are many possible ways to classify innovations. Looking at the production process, for example, we can differentiate among innovations related to a product, to a production process, or to manufacturing. With three types of technological change (new, improved, and existing technology), we find $3^{3}$ or 27 possible combinations. One, for example, would be a new product produced by an existing process in an improved manufacturing system. Innovations might also be classified, according to their economic results, as capital- (material-, energy-, or machine-) saving or as labor-saving.

We might also classify innovations according to

- Class of need satisfied

- Kind of resource saved

- Kind of resource processing system or industry affected

- Change in the relation between extension or rationalization investment

- Source calling for innovation

- Kind of knowledge used

- Cost involved

- Factor determining success

- Consequence

- Share of research and development needed

- Impact on the system's goals

- Component of the production process (e.g., material, machines, manpower, product, process, organization) affected

- Level of administration needed

- Size of firm involved

- Type of property used

- Degree of international competitiveness reached

Groups of interlinked innovations can be found with the help of cluster analysis; the Institute for Economic Research (IFO) study, for example, differentiated between 20 criteria and 274 features of innovation (see Uhlmann 1978). Through cluster analysis, 218 innovations were classified originally into 18 and later into the following 11 significant groups (clusters):

- Market-oriented basic innovations in large-scale organizations (enterprises)

- Cost-reducing innovations within state-owned energy-producing enterprises

- Innovations within leading noncoopera tive technological/industrial organizations

- Market-oriented innovations within leading cooperative private enterprises

- Cost-reducing innovations without external transfer of technology within largescale energy-producing enterprises

-- Innovations based on transfer of technology within small-scale enterprises

- Innovations based on transfer of technology within energy-distributing enterprises

- Innovations adapted by individuals

- Innovations based on trial and error

- Market-oriented basic innovations introduced according to governmental policy

- Routine innovations sponsored by multinational corporations 
We do not think it is possible to construct a universal classification for innovations by using theories or empirically based methods. In establishing a system of classification, we must begin by asking, For what purpose are we doing this? We look at the innovation process from the standpoint of the national economy or its corresponding subsystems. These large systems have three goals:

- To ensure their continuing existence and function by counteracting inhibiting factors

- To ensure the balance of the system by reducing bottlenecks

- To find new ways of ensuring efficiency in a changing environment over a long period

With respect to the impact of a given technological change on a large system, we can differentiate among three functions controlling the system:

- Continuation

- Compensation

- Push

In the energy system, for example, we find the continuing use of existing primary resources. We also encounter bottlenecks in a given energy system, with increasingly negative consequences for its efficiency. It is necessary to compensate for these bottlenecks and to ensure the balance of the entire system by mobilizing new resources. We also find technological changes that not only overcome existing bottlenecks but also establish new ones. These changes act as a stimulus, pushing the existing system over a long period and thus changing it into a new one.

Table 12 shows these functions with respect to two different types of innovation. The first generally concerns giving a push to the technological level (and later, to the efficiency) of an option and often results from overcompensating for existing bottlenecks.

TABLE 12 Types of innovation and their functions.

\begin{tabular}{llll}
\hline & Function & & \\
\cline { 2 - 4 } Type of innovation & Push & Compensation & Continuation \\
\hline Basic (BI) & $\bullet \bullet$ & $\bullet$ \\
Improvement-related (II) & & $\bullet$ & \\
\hline
\end{tabular}

The second deals primarily with continuing well-known processes and compensating for bottlenecks. These two polar types of innovation, basic and improvement-related, are also known by the terminology that follows.

- Basic innovation (BI): fundamental, major, strategic, radical, or discontinuous innovation; revolutionary change

- Improvement-related innovation (II): routine, incremental, minor, tactical, rationalization, or continuous innovation; evolutionary change 


\subsection{The Effect of Basic and Improvement-Related Innovations on Efficiency}

\subsubsection{Optimization of Investments}

The main function of a basic innovation is to give a push to the existing system of technology and to change it into a new system with higher efficiency. The principal function of an improvement-related innovation is to balance a given system by improving its efficiency. As basic innovations are a complex of smaller changes, in one sense the difference between the two types is relative. Basic innovations, however, consist of small changes leading over a decade or so to increasing returns, while improvement-related innovations, starting from the existing technology, lead over a similar time span of 10 years or more to diminishing returns.

The relationship between policies of push and compensation can be demonstrated through the example of investment allocation. All investments in a given industry can be subdivided into

$$
I^{*}=I_{1}+I_{2}+C
$$

where

$I_{1}$ is the investment to overcome bottlenecks with respect to technical equipment (compensation investment), per employee

$I_{2}$ is the investment to introduce new technological solutions (push investment), per employee

$C$ is the investment for replacement (continuation investment), per employee

Optimization is necessary only for

$$
I=I_{1}+I_{2}
$$

The subsequent shares of compensation and push investments are

$$
\begin{aligned}
& i_{1}=I_{1} / I \\
& i_{2}=I_{2} / I
\end{aligned}
$$

and $i_{1}+i_{2}=1$.

If the main criterion for efficiency is labor productivity, we take the replacement coefficient

$$
l_{i}=\frac{L_{0} P^{\prime}-L_{1}}{I} 100(\text { percent })
$$

where

$L_{0,1}$ is the number of employees at time 0 or 1

$P^{\prime}$ is the index of output $\left(P_{1} / P_{0}\right)$

$I$ is investments 
$L_{0}-L_{1}$ is the absolute saving of labor force

$\hat{L}=L_{0} P^{\prime}-L_{1}$ is the relative saving of labor force

The coefficient $l_{i}$ thus shows how many employees are replaced (relatively) by a given sum of investments. This coefficient differs for compensation and push investments, but in both cases we find an invariance: when investing more, replacement coefficient $l_{i}$ increases up to a certain point and then decreases.

Assuming a simple dependency including this invariance, we write

$$
\begin{aligned}
& \hat{l}_{i 1}=a_{12} i_{1}-a_{13} i_{1}{ }^{2} \\
& \hat{l}_{i 2}=a_{22} i_{2}-a_{23} i_{2}{ }^{2}
\end{aligned}
$$

The first coefficient $\hat{l}_{i 1}$ shows the relative replacement over the share of compensation investments $i_{1}$, and the second coefficient $\hat{l}_{i 2}$ shows the relative replacement over the share of push investments. In general, parameters $a_{i j}$ are different in the two cases. Compensation investments initially have rather high replacement effects, which then diminish rapidly; push investments initially have rather low replacement effects, which then increase before diminishing.

The relative economy of labor is the sum of both types of replacements.

$$
\begin{aligned}
& \hat{L}=\hat{L}_{i 1}+\hat{L}_{i 2} \\
& \hat{L}=I_{1} \hat{l}_{i 1}+I_{2} \hat{l}_{i 2} \\
& \hat{L}=I_{1}\left(a_{12} i_{1}-a_{13} i_{1}{ }^{2}\right)+I_{2}\left(a_{22} i_{2}-a_{23} i_{2}{ }^{2}\right)
\end{aligned}
$$

As $i_{1}=1-i_{2}$, we find

$$
\begin{aligned}
& \hat{L}=I\left[i_{2}\left(-2 a_{12}+3 a_{13}\right)+i_{2}{ }^{2}\left(a_{12}-3 a_{13}+a_{23}\right)+i_{2}{ }^{3}\left(a_{13}-a_{23}\right)+a_{12}-a_{13}\right] \\
& \hat{L}=I\left(d_{2} i_{2}+d_{3} i_{2}{ }^{2}+d_{4} i_{2}{ }^{3}+d_{1}\right)
\end{aligned}
$$

From

$$
\begin{aligned}
& \frac{\mathrm{d} \hat{L}}{\mathrm{~d} i_{2}}=I\left(d_{2}+2 d_{3} i_{2}+3 d_{4} i_{2}^{2}\right)=0 \\
& i_{2}^{2}+\frac{2 d_{3}}{3 d_{4}} i_{2}+\frac{d_{2}}{3 d_{4}}=0
\end{aligned}
$$

We obtain the optimal solution

$$
i_{2(1,2)}=-\frac{d_{3}}{3 d_{4}} \pm\left[\left(\frac{d_{3}}{3 d_{4}}\right)^{2}-\frac{d_{2}}{3 d_{4}}\right]^{1 / 2}
$$


Our assumption of two quadratic equations is arbitrary; it might be more appropriate to use an exponential function for this purpose. A more complicated problem is the actual statistical identification of the two types of replacement. We used data from the automobile industry in the GDR from 1955 to 1970 , where motor production showed the typical behavior of compensation investments, with a low increase in equipment per employee. We compared investments of the two types, using the two interlinked subbranches (motor production and car production) of the automobile industry.

We determined the parameters in the following equations by analyzing the time series of investments and replacements of labor:

$$
\begin{aligned}
& \hat{l}_{i 1}=25.0 i_{1}-52.3 i_{1}{ }^{2} \\
& \hat{l}_{i 2}=61.2 i_{2}-72.9 i_{2}{ }^{2}
\end{aligned}
$$

The absolute economy of labor for the 1955-1970 period was

$$
\hat{l}=I\left(106.9 i_{2}-70.7 i_{2}{ }^{2}-20.6 i_{2}{ }^{3}-27.3\right.
$$

The relative economy of labor was

$$
\hat{l}=106.9 i_{2}-70.7 i_{2}{ }^{2}-20.6 i_{2}{ }^{3}-27.3
$$

In

$$
i_{2(1,2)}=-\frac{70.7}{61.8}+\left(\frac{70.7}{61.8}\right)^{2}+\frac{106.9}{61.8}
$$

we find an optimal $i_{2}$ of nearly 60 percent. Then the optimal replacement is

$$
\begin{aligned}
& \hat{l}=6.86 \text { (relative coefficient) } \\
& \hat{L}=126,000 \text { employees }
\end{aligned}
$$

The real economy of labor was $l=5.36$ and $L=96,000$ employees, showing a difference from the optimal solution of 30,000 employees. The share of push investments was actually 33 percent. Of course, estimating investment allocation in the automobile industry is not simply a question of determining the share of push investments by one criterion. Our example merely illustrates the opportunities offered by modeling.

In general, we assume the efficiency of policies of push and compensation shown in Fig. 9. Although given for only one point in time, the figures shown in Table 13 for the energy field reflect the same general pattern (see also Ray 1979).

For short-term planning we prefer a policy of compensation; only for a longer perspective do we choose a policy combining push and compensation. In practice, many basic innovations dominate the efficiency of the entire system only 10 years or more after the first commercial use (Gold 1975). The primary problem is therefore the length of the optimization period. The shorter this period, the more important a policy of pure improvement becomes. The first long-term plan of a national economy oriented toward a basic innovation (electricity) - the so-called GOELRO-plan in the USSR - had a time frame of 10 to 15 years (1920-1935). 


\begin{tabular}{lll}
\hline Push & Compensation & Continuation \\
\hline
\end{tabular}

BI
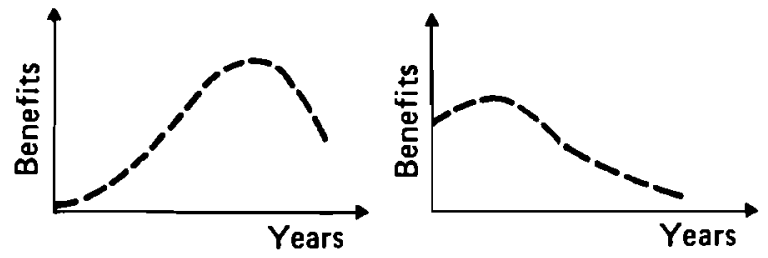

II
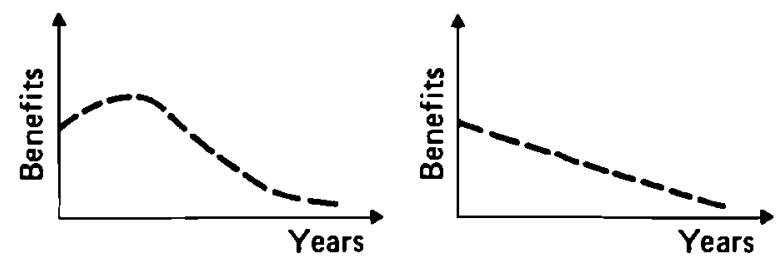

FIGURE 9 Typical progression of benefits over time under three investment policies for basic and improvement-related innovations (BI and II, respectively).

The distinction between $\mathrm{BI}$ and $\mathrm{Il}$, first made by historians (Zvorykin et al. 1962), was a qualitative theoretical approach. We give the terms BI and II (or the revolutionary and evolutionary technological changes cited by Nick (1974)) another interpretation. In many studies the distinction means only a certain degree of technological change. Our starting point is the influence of a given technological change on the socioeconomic system. In any given system, we find a tendency for the average efficiency to stagnate or to decrease. This tendency can be reduced by improvement-related innovations but overcome only by basic innovations whose efficiency is higher than average and whose share in output is sufficient.

While the effects of basic innovations take longer to occur than do those of improvement-related innovations, they are higher. Of course, this does not mean that we can ignore the effects of II, which are comparable over a long period to those of BI. BI and II are two sides of one coin, and the development of metallurgy proves that underestimation of II is as dangerous as fear of BI. Nevertheless, II is not able to ensure the endless efficiency of a large system. Limitless asymptotic increase of efficiency through better balancing of elements is conceivable only for a closed system. When we consider the relations of a large system with the environment, we must take into account the possibility of sudden or tremendous changes, which may lead to major bottlenecks, resource deficits, and conflict situations that can be mastered only through complex, radical solutions. 
TABLE 13 The strategy of technological introduction in the energy field in the US.

\begin{tabular}{|c|c|c|c|}
\hline Impact & Strategy & Technology & $\begin{array}{l}\text { Impact in } \\
\text { year } 2000^{a}\end{array}$ \\
\hline \multirow[t]{2}{*}{$\begin{array}{l}\text { Near-term } \\
\text { (present to } 1985 \text { and beyond) }\end{array}$} & $\begin{array}{l}\text { Increase efficiency of energy use } \\
\text { Convert waste to energy }\end{array}$ & $\begin{array}{l}\text { Conservation in buildings and consumer products } \\
\text { Efficiency in industrial energy use } \\
\text { Efficiency in transportation } \\
\text { Conversion of waste materials to energy }\end{array}$ & $\begin{array}{l}7.1 \\
8.0 \\
9.0 \\
4.9\end{array}$ \\
\hline & $\begin{array}{l}\text { Preserve supplies of oil, gas, and coal } \\
\text { Expand oil, gas, coal, and nuclear options }\end{array}$ & $\begin{array}{l}\text { Direct utilization of coal } \\
\text { Nuclear reactors } \\
\text { Enhanced recovery of oil and gas }\end{array}$ & $\begin{array}{l}24.5 \\
28.0 \\
13.6\end{array}$ \\
\hline $\begin{array}{l}\text { Mid-term } \\
\text { ( } 1985 \text { to } 2000 \text { and bey ond) }\end{array}$ & $\begin{array}{l}\text { Accelerate development of synthetic fuels } \\
\text { from coal and shate } \\
\text { Increase use of underused fuel forms (those } \\
\text { with limited application) } \\
\text { Attract more usable energy from waste heat }\end{array}$ & $\begin{array}{l}\text { Production of gaseous and liquid fuels from coal } \\
\text { Oil shale } \\
\text { Geothermal energy } \\
\text { Solar heating and cooling } \\
\text { Utilization of waste heat }\end{array}$ & $\begin{array}{l}14.0 \\
7.3 \\
3.1-5.6 \\
5.9 \\
4.9\end{array}$ \\
\hline $\begin{array}{l}\text { Long-term } \\
\text { ( } 2000 \text { and beyond) }\end{array}$ & $\begin{array}{l}\text { Develop the technologies necessary to use } \\
\text { essentially inexhaustible fuel resources } \\
\text { Develop the technologies necessary to change } \\
\text { existing distribution systems to accommodate } \\
\text { the distribution of new energy sources }\end{array}$ & $\begin{array}{l}\text { Brecder reactors } \\
\text { Fusion } \\
\text { Solar electric power } \\
\text { Efficiency in electric conversion } \\
\text { Transmission and distribution of electric power } \\
\text { Electric transport } \\
\text { Electric storage } \\
\text { Hydrogen in energy supplies } \\
\text { Fuels from biomass }\end{array}$ & $\begin{array}{l}3.1 \\
- \\
2.1-4.2 \\
2.6 \\
1.4 \\
1.3 \\
- \\
- \\
1.4\end{array}$ \\
\hline
\end{tabular}

$a_{\text {Quads }}=10^{13}$ Btu (British thermal unit).

SOURCE: Adapted from US Energy Research and Development Administration 1976. 
As a result of delay in their realization, basic innovations may have a compensatory function without stimulating efficiency during the first step of application. The energy study conducted by Häfele at IIASA showed that in using final energy we can expect many improvement-related innovations (Energy Systems Program Group of the International Institute for Applied Systems Analysis 1981). This helps us to reduce the primary energy/GDP coefficient in developed countries from the present value of 0.8 to 0.5 and in less-developed countries from 1.5 to 1.0 (Maier 1979). Conversely, the same study indicates that we must be aware of a completely different development with respect to such basic innovations as nuclear energy, synthetic fuels, solar energy, and biogas. In the next two decades, we expect a rising primary energy/GDP coefficient resulting from extensive demand pull and from delay in mastering the economy of basic innovations (see Mensch 1976).

\subsubsection{Potential and Actual Outcomes}

We have mentioned only the functions of innovations that contribute to achieving the goals of large systems. However, some innovations that seem appropriate for meeting the goals of a socioeconomic system or subsystem actually have a generally negative influence on it over a long period. We call such an innovation, the primary or secondary consequences of which damage the system's efficiency, a pseudo innovation (PI). We find many pseudo innovations in the consumer goods industry. In American supermarkets, where about 1500 new products appear each year, less than 20 percent survive more than one year on the shelves; the rest have proved unsellable, faddish, risky, or unprofitable or have been made obsolete by competitors with other new products. Furthermore, positive technological changes with positive socioeconomic potential can appear as innovaticns that have negative effects. $\dagger$ As Table 14 shows, a major technological change (potential BI) may thus occur only as an II or as a PI. The actual outcome depends on the ability to use innovative potential by changing many conditions necessary for optimal efficiency of the new or renewed system. As all these conditions change over time, a potential BI may or may not become an actual BI. For example, automation of the production process in a given (nonautomated) industry is a BI. It may become an II if changing the traditional process is not possible, but such automation without process-related change is not efficient. It may also become a PI; solar energy, for example, is a potential BI that may actually occur only as a PI - as in cases where solar heating systems are installed in existing buildings without changing other conditions. Similarly, an innovation planned as an II might actually function as a BI; we often do not clearly realize the qualitative or quantitative potential of an innovation. A PI might become an II as a result of learning induced by negative results.

As many innovations are closely linked over time, it is important to realize and to promote positive feedbacks in the innovation process. For example, the introduction of the railway system led to higher coal demand, and higher coal demand required better transport, which was possible through the railways. The prehistory and history of basic innovations are made up of groups of small innovations. The incandescent lamp, for example, was a BI in which many small changes were needed, and from Edison's time on, its development has been a complex of improvement-related innovations. We can differentiate

$\dagger$ We refer again to the distinction, made in Section 2.1.1, between innovation and invention. 
TABLE 14 Examples of potential and actual outcomes of basic, improvement-related, and pseudo innovations (BI, II, and PI, respectively).

\begin{tabular}{llll}
\hline Potential outcome & Actual outcome & II & PI \\
\cline { 2 - 3 } & BI & $\begin{array}{l}\text { Automation in connection with new } \\
\text { production processes }\end{array}$ & $\begin{array}{l}\text { Automation without changing the } \\
\text { established production process }\end{array}$ \\
II & Oxygen process in metallurgy & $\begin{array}{l}\text { Improved performance characteristics of } \\
\text { machines }\end{array}$ & $\begin{array}{l}\text { Higher speed and motive power of } \\
\text { automobiles }\end{array}$ \\
PI & Does not occur in reality & $\begin{array}{l}\text { Change in advertising made for the benefit } \\
\text { of the manufacturer but eventually useful } \\
\text { to the consumer }\end{array}$ & $\begin{array}{l}\text { Change in product with no real effect on } \\
\text { the consumer }\end{array}$ \\
\hline
\end{tabular}


between improvement-related innovations leading to basic innovations and improvementrelated innovations using the efficiency potential of basic innovations. BI is the result of a long process of selection in a wide field of smaller innovations that are competing with each other; it is essentially a package of technological changes creating a new system. A new BI establishes a greater potential for efficiency that can be more or less fully mobilized only through many improvement-related innovations. We call this incremental innovation.

\subsubsection{A More Detailed Approach to Classification}

The technological level, range of application, and impact on the national economy of basic innovations differ greatly. The technological level is closely connected with the necessary type and amount of mission-oriented fundamental research, applied research, and development, so it is understandable that the authors of the IFO study proposed to call basic innovations all technological changes that go through research and development stages (Uhlmann 1978). Another extreme is to use the term only for the main historical breakthroughs in technology, such as the steam engine, tool machine, and electricity. We cannot call pure scientific or technical results (inventions) basic innovations, as they are only first steps; their eventual classification depends on the availability of resources, socioeconomic needs, and capability of a given society for mastering the inventions. Thus it is not possible to speak about BI without considering social factors.

We propose calling basic innovations major technological changes that

- Are based on fundamental and applied research

- Have a well-defined high range of application - that is, modify essentially the existing demand or application complex (e.g., synthetic fibers), establish a new demand or application complex (e.g., television), or change the entire system of needs (e.g., production and consumption of electricity)

- Are connected with new scientific/technological principles of a higher order

BI greatly stimulates the entire socioeconomic system, has an enormous potential for efficiency, and is able to arrest or alter the tendency to decreasing efficiency in using resources.

The technological level of innovations is also an important indicator, but its connection with the efficiency of the system affected is not linear. Some basic innovations of the past, such as Hargreaves' machine, were not based on new scientific/technological principles. On the other hand, some innovations of a high scientific/technological level, such as the coal arc lamp of the nineteenth century, have not found a wide range or field of application.

Tables 15 and 16 illustrate various kinds of BI and II. We can also distinguish among three kinds of PI:

PI1 Simple product-related innovations that do not improve the efficiency of the user's system (e.g., many modifications in automobiles)

PI2 Innovations that improve the efficiency of one process but reduce the efficiency of the system as a whole (e.g., plastic materials that are inappropriate for practical needs)

PI3 Innovations that improve the system's efficiency in the short term but eventually lead to large losses or imbalances (e.g., process-related innovations in the chemical industry that later have a negative influence on the environment) 
TABLE 15 Description and examples of three kinds of basic innovation (BI).

\begin{tabular}{|c|c|c|c|c|c|c|c|}
\hline No. & $\begin{array}{l}\text { Type of } \\
\text { innovation }\end{array}$ & $\begin{array}{l}\text { Share of } \\
\text { fundamental } \\
\text { research }\end{array}$ & $\begin{array}{l}\text { Share of } \\
\text { applied } \\
\text { research }\end{array}$ & Range of application & $\begin{array}{l}\text { Impact on } \\
\text { production system }\end{array}$ & $\begin{array}{l}\text { Lag between } \\
\text { invention and } \\
\text { large-scale application }\end{array}$ & Example \\
\hline$\overline{\mathrm{BI} 1}$ & Major & High & High & $\begin{array}{l}\text { Change in entire } \\
\text { system of needs }\end{array}$ & $\begin{array}{l}\text { Change in entire } \\
\text { production system }\end{array}$ & 20 to 60 years & $\begin{array}{l}\text { First industrial } \\
\text { revolution }\end{array}$ \\
\hline $\mathrm{BI} 2$ & Middle & Middle & High & $\begin{array}{l}\text { Establishment of new } \\
\text { demand complex } \\
\text { (or market) }\end{array}$ & $\begin{array}{l}\text { Creation of industrial } \\
\text { branches }\end{array}$ & 20 to 30 years & Microelectronics \\
\hline $\mathrm{BI} 3$ & Minor & Low & Middle & $\begin{array}{l}\text { Essential modification of } \\
\text { existing demand complex }\end{array}$ & $\begin{array}{l}\text { Creation of new lines } \\
\text { of industry }\end{array}$ & 10 to 20 years & Synthetic fibers \\
\hline
\end{tabular}

TABLE 16 Description and examples of four kinds of improvement-related innovation (II).

\begin{tabular}{|c|c|c|c|c|c|c|}
\hline No. & $\begin{array}{l}\text { Type of } \\
\text { innovation }\end{array}$ & $\begin{array}{l}\text { Share of fundamental } \\
\text { and applied research }\end{array}$ & $\begin{array}{l}\text { Share of } \\
\text { development }\end{array}$ & Range of application & Impact on production system & Example \\
\hline II 1 & Very important & Middle & High & $\begin{array}{l}\text { Establishment of new demand } \\
\text { complex (or market); new } \\
\text { product in existing demand } \\
\text { complex }\end{array}$ & $\begin{array}{l}\text { Creation of new industrial } \\
\text { subbranches }\end{array}$ & Polyester \\
\hline II 2 & Important & Low & Middle & $\begin{array}{l}\text { Essential moditication of } \\
\text { existing demand complex; } \\
\text { new parameters of } \\
\text { well-known products }\end{array}$ & $\begin{array}{l}\text { Creation of new product } \\
\text { lines or processes }\end{array}$ & $\begin{array}{l}\text { Thomas-gilchrist process } \\
\text { Electric toothbrush }\end{array}$ \\
\hline II3 & $\begin{array}{l}\text { Normal } \\
\text { (incremental) }\end{array}$ & None & Low or none & $\begin{array}{l}\text { Simple modification of } \\
\text { existing demand complex; } \\
\text { improved parameters of } \\
\text { well-known products }\end{array}$ & $\begin{array}{l}\text { Improvement in product } \\
\text { lines or processes }\end{array}$ & Fluoride toothpaste \\
\hline II4 & $\begin{array}{l}\text { Evolutionary } \\
\text { change } \\
\text { (marginal) }\end{array}$ & None & None & Little improvement & Little improvement & $\begin{array}{l}\text { Better "touch" on } \\
\text { telephones }\end{array}$ \\
\hline
\end{tabular}


Classification of three kinds of BI, four kinds of II, and three kinds of PI gives us the following ten kinds of innovation (I1-I10):

\begin{tabular}{cccccccccc} 
& \multicolumn{9}{c}{ I } \\
& BI & \multicolumn{9}{c}{ II } & & & & \\
BI1 & BI2 & B13 & II1 & II2 & II3 & II4 & PI1 & PI2 & PI3 \\
I1 & I2 & I3 & I4 & I5 & I6 & I7 & I8 & I9 & I10
\end{tabular}

Looking at the ocean of innovations of course reveals a continuum not measurable by one clear indicator. Rather than considering this only as a continuum, however, we must take into account the obvious turning or breakeven points in complexity, efficiency, and manageability in the total field of innovation. For instance, in socialist countries each scientific/technological task of one planning cycle is associated with one level of administration, from the firm to the national economy. Each type of task has various prerequisites in management and planning.

These are the most important relationships from our viewpoint; we do not want a complete or eclectic classification of all kinds of innovation. Instead, we concentrate on the process of transition from a given structure of technologies to a new structure that is able to overcome socioeconomic bottlenecks and major gaps in resource processing systems. Table 17 shows a more sophisticated classification by technological level and range of application that enables us to differentiate among 49 kinds of innovation.

\subsubsection{An Innovation Level Index}

The next step in establishing an innovation classification could be a quantitative evaluation by a technology level index. This step was made in an OECD investigation of 1246 innovations in five countries from 1953 to 1973 (see Table 18). While the linear level index used by the OECD study is given in column (1) of Table 18, we think that an exponential level index (column (2)) is more appropriate because the distance between basic and improvement-related innovations should be greater than the distance between different kinds of improvement-related innovations. The frequency distribution in column (4) also points to an exponential pattern. Another argument is the exponential growth of technological parameters during the transition to new principal solutions and the exponential saturation in the period of improvement. If we assume that the importance of innovations $w$ (a coefficient between 1 and 100) follows an exponential function and the two parameters $i_{k}$ and $v_{k}$ are connected in a multiplicative form, we can write

$$
\begin{aligned}
& w=i_{k} v_{k} \\
& w=\mathrm{e}^{a k} \mathrm{e}^{b k} \\
& w=\mathrm{e}^{(a+b) k}
\end{aligned}
$$

Taking a simple symmetrical scheme $(a=b)$, we then have

$$
w=e^{2 a k} \quad k=0,1, \ldots, 6
$$


TABLE 17 Classification of innovations by scientific/technological level and range of application.

\begin{tabular}{|c|c|c|c|c|c|c|c|c|c|}
\hline \multirow[b]{3}{*}{ No. } & \multirow[b]{3}{*}{$\begin{array}{l}\text { Scientific/ } \\
\text { technological } \\
\text { level }\end{array}$} & \multirow[b]{3}{*}{$\nu_{k}$} & \multicolumn{7}{|c|}{ Range of application } \\
\hline & & & \multicolumn{4}{|l|}{ II } & \multicolumn{3}{|l|}{ BI } \\
\hline & & & $\begin{array}{l}\text { Quantitative } \\
\text { growth of } \\
\text { existing demand }\end{array}$ & $\begin{array}{l}\text { Simple modifica- } \\
\text { tion of existing } \\
\text { demand complex } \\
\text { (improved param- } \\
\text { eters of existing } \\
\text { products or } \\
\text { processes) }\end{array}$ & $\begin{array}{l}\text { Essential modifi- } \\
\text { cation of existing } \\
\text { demand complex } \\
\text { (new parameters } \\
\text { of existing } \\
\text { products and } \\
\text { processes) }\end{array}$ & $\begin{array}{l}\text { Development of } \\
\text { new demand } \\
\text { (new product } \\
\text { or process) in } \\
\text { existing demand } \\
\text { complex }\end{array}$ & $\begin{array}{l}\text { Essential modifi- } \\
\text { cation of existing } \\
\text { demand complex } \\
\text { (new products } \\
\text { or processes) }\end{array}$ & $\begin{array}{l}\text { Development of } \\
\text { new demand } \\
\text { complex or } \\
\text { subcomplex }\end{array}$ & $\begin{array}{l}\text { Change in } \\
\text { entire } \\
\text { system } \\
\text { of needs }\end{array}$ \\
\hline & $i_{k}$ & & 1 & 1.5 & 2.2 & 3.2 & 4.6 & 6.8 & 10 \\
\hline 1 & $\begin{array}{l}\text { Quantitative } \\
\text { growth of existing } \\
\text { technical basis }\end{array}$ & 1 & 1 & 1.5 & 2.2 & 3.2 & 4.6 & 6.8 & 10 \\
\hline 2 & $\begin{array}{l}\text { Improvement } \\
\text { within well-known } \\
\text { technical principle }\end{array}$ & 1.5 & 1.5 & 2.3 & $\begin{array}{l}3.5 \\
\text { (Bentwood } \\
\text { furniture) }\end{array}$ & $\begin{array}{l}4.8 \\
\text { (Bicycle) }\end{array}$ & 6.9 & 10 & 15 \\
\hline 3 & $\begin{array}{l}\text { Improvement } \\
\text { within well-known } \\
\text { technical principle } \\
\text { with essential } \\
\text { changes in one } \\
\text { factor (materials, } \\
\text { tools, or function } \\
\text { design) }\end{array}$ & 2.2 & 2.2 & $\begin{array}{l}3.3 \\
\text { (Oxygen process) }\end{array}$ & $\begin{array}{l}4.8 \\
\text { (Thomas-gilchrist } \\
\text { process) }\end{array}$ & $\begin{array}{l}7 \\
\text { (Diesel engine) }\end{array}$ & $\begin{array}{l}10 \\
\text { (Paper } \\
\text { production) }\end{array}$ & 15 & 22 \\
\hline 4 & $\begin{array}{l}\text { Improvement } \\
\text { within well-known } \\
\text { technical principle } \\
\text { with essential } \\
\text { changes in several } \\
\text { factors }\end{array}$ & 3.2 & 3.2 & 4.8 & (Stitching bond) & $\begin{array}{l}10 \\
\text { (Atomic } \\
\text { ice-breakers) }\end{array}$ & $\begin{array}{l}15 \\
\text { (Electric railway) }\end{array}$ & 22 & $\begin{array}{l}33 \\
\text { (Spinning } \\
\text { jenny) }\end{array}$ \\
\hline 5 & $\begin{array}{l}\text { New solutions } \\
\text { within well-known } \\
\text { basic principle }\end{array}$ & 4.6 & 4.6 & 6.9 & $\begin{array}{l}10 \\
\text { (Gyrocompass) }\end{array}$ & $\begin{array}{l}15 \\
\text { (Polyethylene) }\end{array}$ & $\begin{array}{l}22 \\
\text { (Detergents) }\end{array}$ & $\begin{array}{l}33 \\
\text { (Vacuum lamp) }\end{array}$ & 46 \\
\hline 6 & $\begin{array}{l}\text { New basic princi- } \\
\text { ple within same } \\
\text { form or structural } \\
\text { level of matter }\end{array}$ & 6.8 & 6.8 & 10 & 15 & 22 & $\begin{array}{l}33 \\
\text { (Synthetic fibers) }\end{array}$ & $\begin{array}{l}46 \\
\text { (Incandescent } \\
\text { lamp) }\end{array}$ & 68 \\
\hline 7 & $\begin{array}{l}\text { New basic princi- } \\
\text { ple changing form } \\
\text { or structural level } \\
\text { of matter }\end{array}$ & 10 & 10 & 15 & 22 & 33 & $\begin{array}{l}46 \\
\text { (Radar) }\end{array}$ & $\begin{array}{l}68 \\
\text { (Transistor) }\end{array}$ & $\begin{array}{l}100 \\
\text { (Electricity) }\end{array}$ \\
\hline
\end{tabular}

NOTE: Examples are given for illustrative purposes in some cases. 
TABLE 18 Level and frequency of innovative activities in five OECD countries, 1953-1973.

\begin{tabular}{lcccc}
\hline & $\begin{array}{l}\text { Linear level } \\
(0-100)\end{array}$ & $\begin{array}{l}\text { Exponential level } \\
(1-100)\end{array}$ & $\begin{array}{l}\text { Frequency } \\
\text { (absolute) }\end{array}$ & $\begin{array}{l}\text { Frequency } \\
\text { (percent) }\end{array}$ \\
\cline { 2 - 5 } Type & $(1)$ & $(2)$ & $(3)$ & $(4)$ \\
\hline Marginal & $0-44$ & $1-2$ & 760 & 61 \\
Normal II & $45-55$ & $3-5$ & 239 & 19 \\
Important II & $56-66$ & $6-10$ & 149 & 12 \\
Very important II & $67-78$ & $11-21$ & 62 & 5 \\
Radical II & $79-89$ & $22-46$ & 29 & 2 \\
BI & $90-100$ & $47-100$ & 7 & 1 \\
& $0-100$ & $1-100$ & 1246 & 100 \\
\hline
\end{tabular}

SOURCE for columns (1), (3), and (4): OECD Study as cited in Mensch 1976.

According to $1 \leqslant w \leqslant 100$ (percent), we find for $k=6$

$$
\begin{aligned}
100 & =\mathrm{e}^{12 a} \\
a & =-\frac{\ln 100}{12}=0.38376
\end{aligned}
$$

From this we find the coefficients of importance for each level within the $7 \times 7=49$ field (see Table 17).

When we try to adjoin one innovation to the $7 \times 7=49$ field, we realize that we often have difficulty in making an exact estimation; we thus find it inappropriate to make the classification too sophisticated. This does not mean that for special studies and innovations we do not need a more detailed typology.

Stages, classes, and types derived from a single innovation process are an important analytical tool, but they are not so useful in studying the behavior of industrial organizations. We must relate the innovation process to the activities and life cycles of industrial organizations and examine the process in relation to the growth of efficiency in industries, corporations, and enterprises.

\section{INDUSTRIAL ORGANIZATIONS AND EFFICIENCY: A SYNTHETIC APPROACH}

\subsection{Innovative Activities in the Life Cycles of Industrial Organizations}

Firms that have been successful for decades may suddenly fall back in their economic performance because of stagnation in an entire branch of the industry, the cumulative effects of years of mismanagement, or insufficient adaptation to market changes. In these situations measures that once had positive results often complete the disaster. For example, diversification sometimes is a profitable strategy and sometimes produces failure. Often an innovation itself becomes a failure, as in the case of the video disc, a record for video reproduction.

Why might the same factors or determinants have different consequences? In our opinion, the main reason lies in the trade-off between the discontinuous pattern of technological progress and the continuous pattern of human learning, or - put more broadly - in 
the incongruity and contradictions between technological and social progress (see Goldberg 1980).

From the standpoint of an industrial organization, the innovation process includes the life cycles of:

- The generic product of the broader, defined area of activity (including a sum of shorter life cycles of single products)

- The generic process (including a sum of shorter life cycles of single processes)

- An industry (including a sum of shorter life cycles of production units)

- The management in one industrial organization (including managerial organization and the qualifications and capabilities of managerial personnel)

The interaction of these life cycles against the background of the entire business and the national economy produces the efficiency cycle.

Observation of the life cycles of products and processes can be important for the allocation of resources in research and development. Patent applications are good indicators; they can be an early warning, at least in the case of investment policy. For example, a stitching bond (Nähwirken) invented in the GDR after the Second World War was an enormously productive textile process. Figure 10 shows that the number of applications for patents on the stitching bond in the US, GDR, UK, FRG, Czechoslovakia, and France

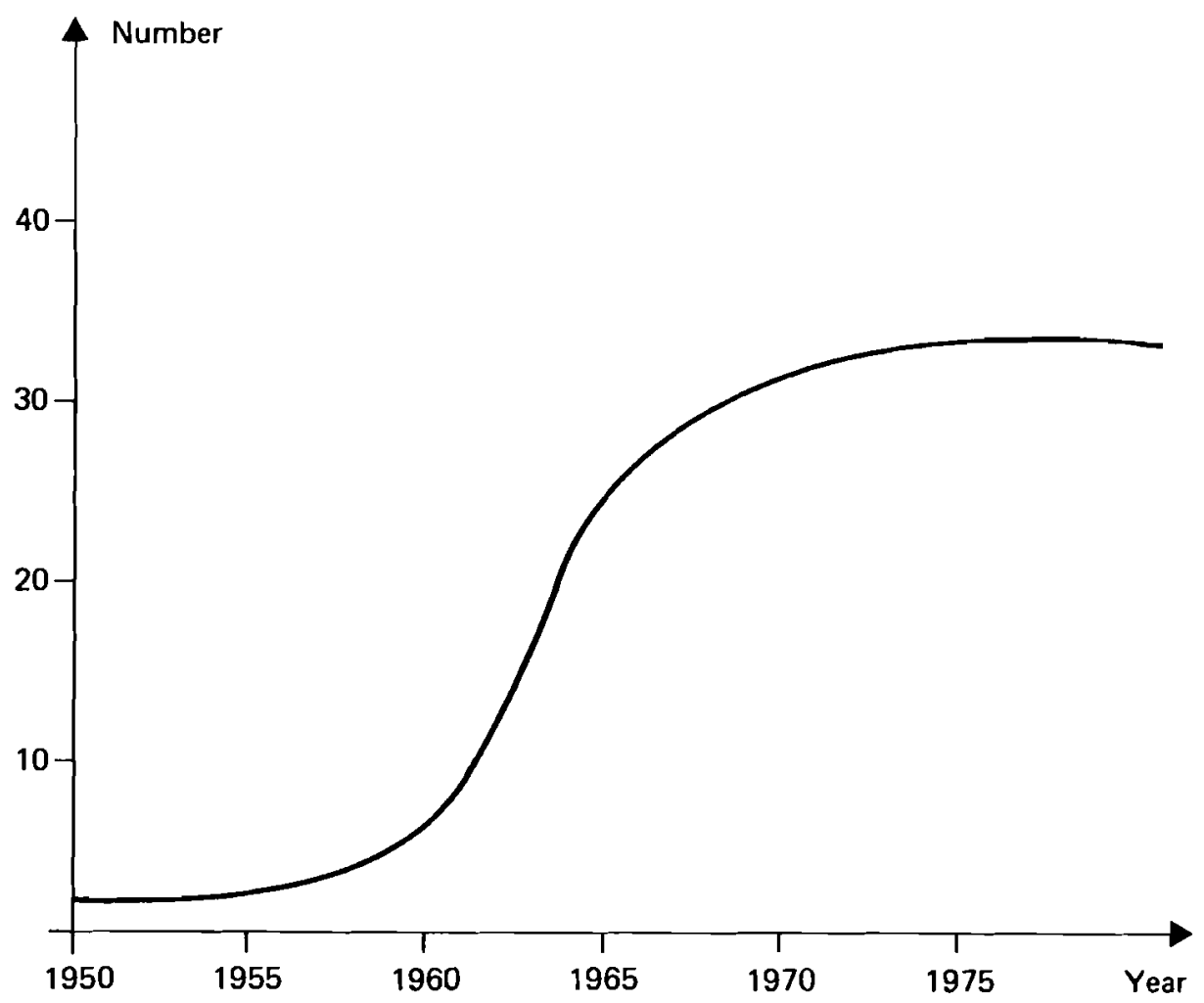

FJGURE 10 Number of applications for patents on the stitching bond in the US, GDR, 1;K, FRG, Czechoslovakia, and France. 
was as follows: $1950-55,1 ; 1956-60,4 ; 1961-65,20 ; 1966-70,31$; and $1971-75,32$. Production of the stitching bond, which is now used in 35 countries, is still in the stage of rapid growth, showing that saturation in patent applications is reached long before saturation in production growth.

The life cycles of products and processes are primarily technological life cycles, while those of industries and management are more complex and socially determined. Life cycles of products and processes are well-known phenomena; Abernathy (1978) and Abernathy and Utterback (1978) analyzed the interrelationship of these two cycles in the automobile industry.

Another life cycle also found in industry is more complex and includes changes in technology, organization, and qualifications of personnel. This is the life cycle of the entire manufacturing process in a given production unit (see Fig. 11). The modernization cycle

$\mid$\begin{tabular}{cll}
$S_{00}$ & Starting up of production \\
$J_{00}$ & First improvement stage \\
$E_{00}$ & First enlargement \\
$J_{01}$ & Second improvement stage \\
$L_{00}$ & First local modernization \\
$J_{02}$ & Third improvement stage \\
$\cdot$ & \\
$\cdot$ & \\
\hline$M_{11}$ & First total modernization \\
$J_{11}$ & First improvement stage after total modernization \\
$L_{11}$ & First local modernization after total modernization \\
$\cdot$ & \\
$\cdot$ & \\
$M_{21}$ & Second total modernization \\
$\cdot$ &
\end{tabular}

FIGURE 11 Life cycle of a production unit.

is the time between two total modernizations of the entire production unit. In the textile industry of the GDR, this has been approximately 25 years and is now approximately 18 years on the average; it may be shorter or longer in other industries.

The problem for management on the corporate level is to synchronize the individual modernization cycles of production units, including shutdowns and new establishments, to the product and process cycles and to the human factor, including changes in managerial organization and in the qualifications and capabilities of managerial personnel. The life cycle of management for European industrial organizations may be different from that in 
the United States. We often find a certain type of conservative manager in traditional branches and more dynamic people in more dynamic branches. When sudden changes occur in traditional industries, we can expect a complicated process of adaptation.

In analyzing the factors affecting innovations in order to grasp the human factor, we found four determinants of success or failure: innovative potential, strategic orientation, capacity for mastering ongoing processes, and cooperation and coordination. These are of varying importance in research and development, production, and marketing. The human capacity is at the same time a social capacity. Social organization and learning can change the pattern of efficiency, which is originally determined by technological progress; as yet, however, no studies have dealt with the interference between technological cycles and cycles of organization, qualification, and management.

The experience of Ericsson, a Swedish company, provides an example of the decisiveness of the human and social factor. This firm changed successfully from electromechanical to electronic telephone exchanges. It was able to do so because its managers succeeded in persuading hundreds of department chiefs to abandon their traditional working procedures and to begin a new experience. On the other hand, the conservative business ideology evident in the saturation stage of an industry creates barriers to innovation at this stage. It is responsible for a growing insistence on short-term efficiency, the "not invented here" syndrome, the formalization of short-term activities that discourage longer-term innovation projects, and a preference for a policy of compensation.

Newly established technological systems bring about new kinds of imbalance and great opportunities for such a policy. From a short-term perspective, a policy of compensation offers more benefits than does a push policy, but it can undermine the development of new possibilities. We must therefore stress again our theoretical concept of dynamic efficiency and stability. Dynamic efficiency, a kind of relative efficiency, is the real efficiency of a production system in relation to a normative efficiency or to the average efficiency of the industry as a whole. Therefore, efficiency of a production unit is a function not only of the particular cycle but also of the industrial cycle as a whole. Dynamic stability is derived from dynamic efficiency, which can be ensured only by a trade-off between push processes, which change the production system, and those of compensation, which improve it. We identify this trade-off as dynamic stability. Relative efficiency develops over the four stages in the shape shown in Fig. 12. In the maturation stage benefits are the highest in absolute measure. We cannot judge only from the standpoint of relative measures; a high profit rate may be nothing if it refers to negligible outputs.

\subsection{Determinants of Innovative Activities in Industrial Organizations}

\subsubsection{Factor Analysis}

Factor analysis of innovations can be made for various purposes. Many such analyses exist in the literature, as, for example, the study by Myers and Marquis (1969), the report on project SAPPHO(Science Policy Research Unit of the University of Sussex 1972), "The Flow of the Industrial Innovation Process" among the 218 cases cited by Uhlmann (1978), and others. The Myers/Marquis study provided an overview of factors affecting innovations and their proportions in various branches. Project SAPPHO compared pairs of successful and unsuccessful innovations, with statistical results indicating that innovations that had achieved commercial success could be distinguished from those that had failed by superior performance in five major areas: 


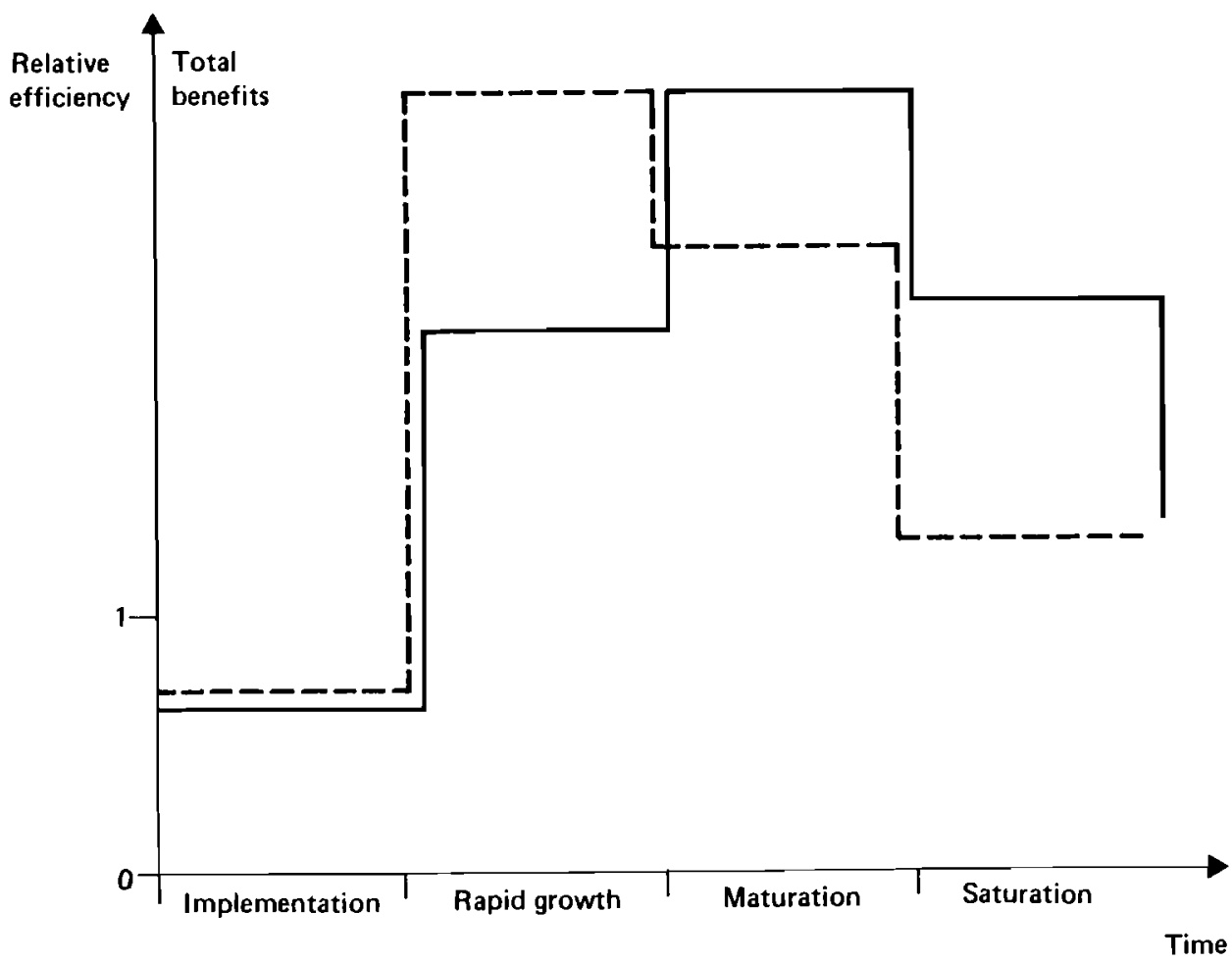

FIGURE 12 The development of relative efficiency over the stages of the innovation process, with efficiency coefficient $e(---)$ and benefits total $E(-\infty)$.

- Strength of management and characteristics of managers

- Understanding of users' needs

- Marketing and sales performance

- Efficiency of development

- Effectiveness of communications

The Uhlmann study attempted to identify types of innovations that could be distinguished from each other by various kinds of factor combinations. All these studies were intended to serve the specific purposes of market economies, but they included not only market activities of corporations and enterprises, but also the impact of governmental policy on innovation.

\subsubsection{Our Investigation of 32 Firms and Its Results}

Central management and planning play an important role in planned economies, but we cannot ignore the activity of enterprises with respect to the market. We wanted to answer two questions through factor analysis: How strong is the influence of factors inhibiting the innovation process on the level of state-owned enterprises? And how strong is the influence of a firm's own ideas and measures in overcoming bottlenecks in and barriers to the innovation process? 
We formulated the 26 variables shown in Table 19. We then questioned managers from 15 state-owned enterprises, using a list initially consisting of 20 and eventually including these 26 variables. We randomly chose 32 successful innovations ( 9 products, 9 production processes, 7 materials, and 7 manufacturing processes) in 32 enterprises, and asked the managers responsible for these enterprises the following questions:

- What inhibiting intensity $p$ did the 26 variables have for the innovation concerned?

- What promoting intensity $q$ did the firm's own measures have for these variables?

We asked them to rate the degree of influence according to a scale of 0 for no importance, 1 for little importance, 2 for medium importance, 3 for great importance, and 4 for very great importance. Our aim was to identify the firm's capacity to overcome barriers to and bottlenecks in the innovation process. We expected some correlation between the inhibiting intensity of the variables and the promoting intensity of the firm's activities.

The correlation coefficient between $p$ and $q$ was 68.82 percent over 32 innovations and 79.22 percent over 26 variables. Both are statistically significant at an error level of less than 0.1 percent. We needed to investigate more closely the specific patterns of influence for certain combinations of variables. Table 19 shows the number of statistically significant correlations between the variables. According to this and to the average values of $p$ and $q$ we obtained the results shown in Table 20 .

The five most important variables inhibiting innovation in the 32 firms were

- Inability to master the process after release by the development group (6) Insufficient supply of machines and means of rationalization (4)

- Differences of opinion between managers and experts (10)

- Developmental failures not abandoned (5)

- Failures of management: insufficient interest on the part of managers (8)

The five most frequently interlinked variables inhibiting innovation were

- Differences of opinion between managers and experts (10)

- Conservative and obsolete views (15)

- Uncoordinated development among several branches (24)

- New solutions replacing the initial project (26)

- Changing demand (18)

The five most important variables promoting innovation were

- Better coordination with management (9)

- Own production of means of rationalization (4)

- Reduction of failures in developmental stages (5)

- Improvement in management (8)

- Improvement in technological and qualitative level (14)

The five most frequently interlinked variables promoting innovation were

- Better transfer of know-how between branches (20) 
TABLE 19 Number of statistically significant correlation coefficients between 26 variables influencing innovations for inhibiting intensity $p$ and promoting intensity $q$.

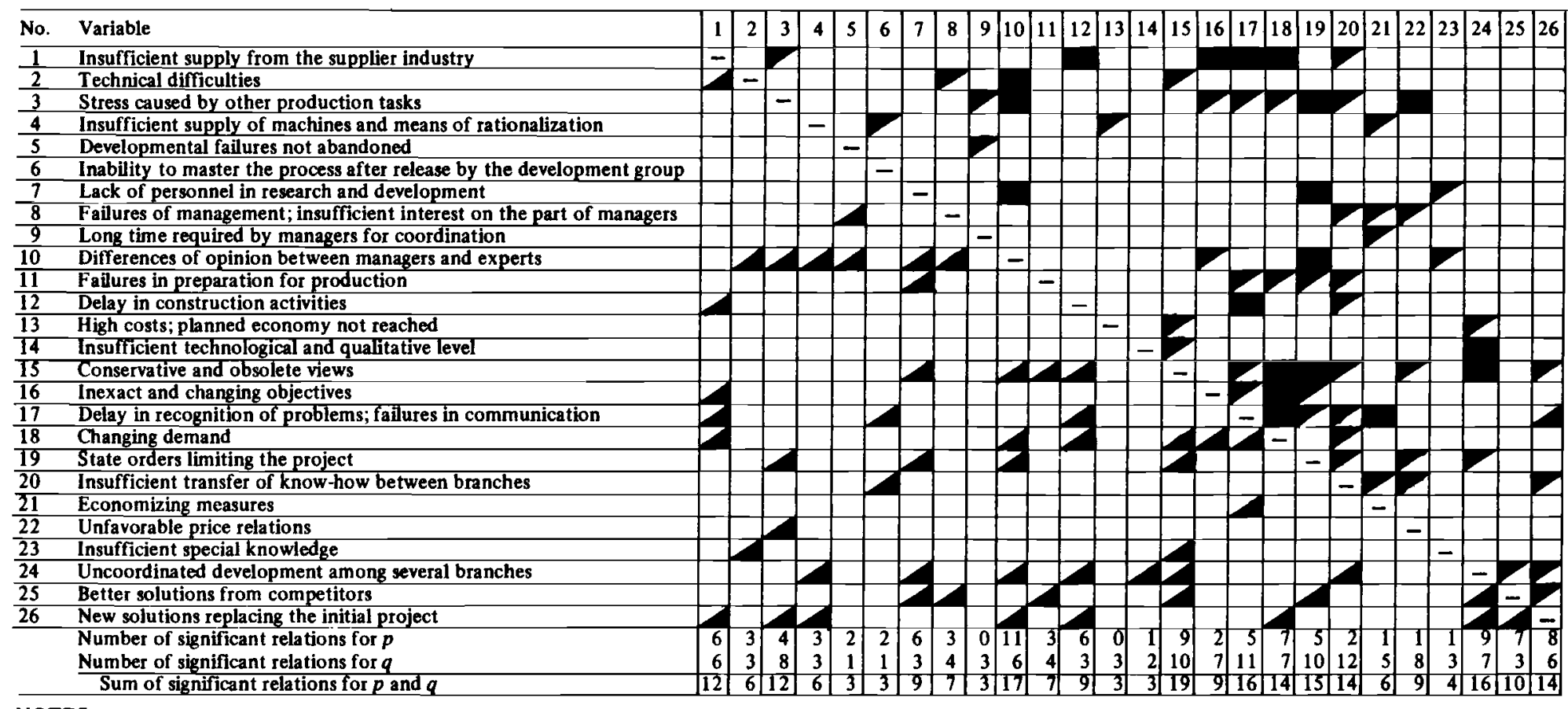

Correlation for $p$.

Correlation for $q$.

Correlation for both $p$ and $q$.

Level of significance: 0.05 . 
TABLE 20 Variables influencing innovations in 32 enterprises, with their inhibiting intensity $p$ and promoting intensity $q$.

\begin{tabular}{rlrr}
\hline No. & Variable & $\Sigma p$ & $\Sigma q$ \\
\hline 1 & Insufficient supply from the supplier industry & 19 & 18 \\
2 & Technical difficulties & 10 & 6 \\
3 & Stress caused by other production tasks & 12 & 9 \\
4 & Insufficient supply of machines and means of rationalization & 2 & 2.5 \\
5 & Developmental failures not abandoned & 4 & 2.5 \\
6 & lnability to master the process after release by the development group & 1 & 10.5 \\
7 & Lack of personnel in research and development & 24 & 23 \\
8 & Failures in management; insufficient interest on the part of managers & 5 & 4.5 \\
9 & Long time required by managers for coordination & 7 & 1 \\
10 & Differences of opinion between managers and experts & 3 & 14 \\
11 & Failures in preparation for production & 25 & 25 \\
12 & Delay in construction activities & 17 & 19.5 \\
13 & High costs; planned economy not reached & 8 & 7 \\
14 & Insufficient technological and qualitative level & 11 & 4.5 \\
15 & Conservative and obsolete views & 18 & 16 \\
16 & Inexact and changing objectives & 13 & 22 \\
17 & Delay in recognition of problems; failures in communication & 21 & 19.5 \\
18 & Changing demand & 26 & 24 \\
19 & State orders limiting the project & 22 & 21 \\
20 & Insufficient transfer of know-how between branches & 23 & 26 \\
21 & Economizing measures & 15 & 12.5 \\
22 & Unfavorable price relations & 16 & 8 \\
23 & Insufficient special knowledge & 6 & 17 \\
24 & Uncoordinated development among several branches & 14 & 12.5 \\
25 & Better solutions from competitors & 9 & 10.5 \\
26 & New solutions replacing the initial project & 20 & 15 \\
\hline & & &
\end{tabular}

- Faster recognition of problems and improvement in communication (17)

- Better adaptation to new state orders and laws (19)

- Positive changes in views and approaches (15)

- Reduction in stress caused by other production tasks (3)

\subsubsection{An Approach to Finding the Main Determinants of Innovation}

Our discussions with managers confirmed that the ability to master the innovation process is a complex phenomenon. Some specialists stress the importance of creative or innovative potential, but if this potential is not used appropriately, the results will be inadequate. A second major factor is thus the firm's long-term strategic orientation. Yet even with considerable potential for innovation and an appropriate strategy, the process might be arrested by stress resulting from other production tasks. The capacity for mastering ongoing processes is therefore a third factor. As the innovation process is complex, touching the entire network of supplier and buyer relations, a fourth factor involves cooperation and coordination. These four determinants are related to at least some extent to the main stages of the innovation process and thus led us to the analytical scheme shown in Table 21.

We adjusted the 26 variables to the four determinants $(I, S, O, C)$ in research and development, production, marketing, and in management at all stages by our assumptions of their dependencies. To prove this we used multivariate factor analysis, which enables us to identify the main factors among many variables by investigating their latent intercorrelation. In this case we used as a criterion the so-called factor loading of a variable at 
TABLE 21 Determinants of innovation, as measured by variables, in research and development, production, marketing, and management.

\begin{tabular}{|c|c|c|c|c|c|c|}
\hline \multirow{3}{*}{$\frac{\text { Determinant }}{\text { Innovative potential }(I)}$} & \multicolumn{6}{|c|}{ Variables } \\
\hline & \multicolumn{2}{|c|}{$\begin{array}{l}\text { In research and } \\
\text { development }\end{array}$} & \multirow{2}{*}{$\frac{\text { In production }}{2}$} & \multirow{2}{*}{$\begin{array}{l}\text { In marketing } \\
4\end{array}$} & \multicolumn{2}{|c|}{$\begin{array}{l}\text { In management } \\
\text { (all stages) }\end{array}$} \\
\hline & 2 & 11 & & & 6 & 15 \\
\hline & 5 & 14 & 6 & & 8 & 23 \\
\hline & 7 & 26 & 13 & & 10 & \\
\hline \multirow[t]{3}{*}{ Strategic orientation $(S)$} & 1 & 17 & 22 & 18 & 9 & 16 \\
\hline & 7 & & & & 10 & 17 \\
\hline & 14 & & & & 15 & \\
\hline \multirow{3}{*}{$\begin{array}{l}\text { Capacity for mastering ongoing } \\
\text { processes }(O)\end{array}$} & 3 & & 3 & 18 & 8 & \\
\hline & 7 & & 13 & & 9 & \\
\hline & & & 21 & & 10 & \\
\hline \multirow[t]{3}{*}{ Cooperation and coordination $(C)$} & 1 & & 1 & 20 & 1 & 17 \\
\hline & 4 & & 4 & 25 & 9 & 19 \\
\hline & 24 & & 20 & & 10 & \\
\hline
\end{tabular}

a level of at least \pm 0.40 . We were able to identify 7 factors in the case of variables inhibiting innovation (see Table 22) and 7 factors in the case of variables promoting innovation (see Table 23). Adjusting these factors to determinants and stages of the innovation process produces the following results:

A. Variables inhibiting innovation

$\begin{array}{ll}\text { Factor } & \text { Determinant } \\ 1 & \text { Innovative potential }(I) \\ 2 & \text { Strategic orientation }(S) \\ 3 & \text { Cooperation and coordination }(C) \\ 4 & \text { Economic mechanism }(E) \\ 5 & \text { Know-how }(K) \\ 6 & \text { Cost } \\ 7 & -\end{array}$

Stage

Research and development All (management)

Research and development

All (management)

All (management)

All (management)

All (management)

B. Variables promoting innovation

$\begin{array}{lll}\text { Factor } & \text { Determinant } & \text { Stage } \\ 1 & \text { Strategic orientation }(S) & \text { Research and devel } \\ 2 & \text { Cooperation and coordination }(C) & \text { Research and devel } \\ 3 & \text { Strategic orientation }(S) & \text { All (management) } \\ 4 & \text { Cooperation and coordination }(C) & \text { All (management) } \\ 5 & \text { Capacity for mastering ongoing processes }(O) & \text { All (management) } \\ 6 & \text { Innovative potential }(I) & \text { Production } \\ 7 & - & \text { All (management) }\end{array}$

While innovative potential, strategic orientation, and cooperation and coordination are the main determinants connected to variables inhibiting innovative activities, innovative potential does not play such an important role on the side of variables promoting innovative 
TABLE 22 Variables inhibiting innovation and their factor configurations.

\begin{tabular}{|c|c|c|c|c|c|}
\hline No. & Variable & $\begin{array}{l}\text { Loading } \\
\text { factor }\end{array}$ & No. & Variable & $\begin{array}{l}\text { Loading } \\
\text { factor }\end{array}$ \\
\hline Factor 1 & & & Factor 4 & & \\
\hline 11 & Failures in preparation for production & 0.81 & 22 & Unfavorable price relations & 0.75 \\
\hline 7 & Lack of personnel in research and development & 0.69 & 3 & Stress caused by other production tasks & 0.74 \\
\hline 15 & Conservative and obsolete views & 0.63 & 19 & State orders limiting the project & 0.46 \\
\hline 25 & Better solutions from competitors & 0.62 & & & \\
\hline 19 & State orders limiting the project & 0.41 & Factor 5 & & \\
\hline Factor 2 & & & 6 & $\begin{array}{l}\text { Inability to master the process after release by the } \\
\text { development group }\end{array}$ & 0.72 \\
\hline 18 & Changing demand & 0.74 & 2 & Technical difficulties & 0.60 \\
\hline 16 & Inexact and changing objectives & 0.70 & 23 & Insufficient special knowledge & 0.42 \\
\hline 1 & Insufficient supply from the supplier industry & 0.66 & & & \\
\hline 17 & $\begin{array}{l}\text { Delay in recognition of problems; failures in } \\
\text { communication }\end{array}$ & 0.55 & $\begin{array}{l}\text { Factor } 6 \\
13\end{array}$ & High costs; planned economy not reached & 0.62 \\
\hline 12 & Delay in construction activities & 0.52 & $\begin{array}{l}21 \\
19\end{array}$ & $\begin{array}{l}\text { Economizing measures } \\
\text { State orders limiting the project }\end{array}$ & $\begin{array}{l}0.42 \\
0.41\end{array}$ \\
\hline Factor 3 & & & & & \\
\hline 21 & Economizing measures & 0.64 & 8 & Failures in management; insufficient interest on the & 0.67 \\
\hline 4 & $\begin{array}{l}\text { Insufficient supply of machines and nieans of } \\
\text { rationalization }\end{array}$ & 0.61 & 10 & $\begin{array}{l}\text { part of managers } \\
\text { Differences of opinion between managers and experts }\end{array}$ & 0.58 \\
\hline 26 & New solutions replacing the initial project & 0.55 & 5 & Developmental failures not abandoned & 0.54 \\
\hline 12 & Delay in construction activities & 0.41 & & & \\
\hline
\end{tabular}


TABLE 23 Variables promoting innovation and their factor configurations.

\begin{tabular}{|c|c|c|c|c|c|}
\hline No. & Variable & $\begin{array}{l}\text { Loading } \\
\text { factor }\end{array}$ & No. & Variable & $\begin{array}{l}\text { Loading } \\
\text { factor }\end{array}$ \\
\hline \multicolumn{3}{|l|}{ Factor 1} & \multicolumn{3}{|l|}{ Factor 4} \\
\hline 17 & $\begin{array}{l}\text { Delay in recognition of problems; failures in } \\
\text { communication }\end{array}$ & 0.87 & 4 & $\begin{array}{l}\text { Insufficient supply of machines and means of } \\
\text { rationalization }\end{array}$ & 0.88 \\
\hline 20 & Insufficient transfer of know-how between branches & 0.84 & 21 & Economizing measures & 0.62 \\
\hline 12 & Delay in construction activities & 0.64 & 1 & Insufficient supply from the supplier industry & 0.41 \\
\hline 11 & Failures in preparation for production & 0.59 & 13 & High costs; planned economy not reached & 0.41 \\
\hline 15 & Conservative and obsolete views & 0.42 & & & \\
\hline \multirow[t]{2}{*}{1} & Insufficient supply from the supplier industry & 0.40 & \multicolumn{3}{|l|}{ Factor 5} \\
\hline & & & 3 & Stress caused by other production tasks & 0.63 \\
\hline \multicolumn{3}{|l|}{ Factor 2} & 10 & Differences of opinion between managers and experts & 0.50 \\
\hline 25 & Better solutions from competitors & 0.71 & 14 & Insufficient technological and qualitative level & 0.45 \\
\hline 24 & Uncoordinated development among several branches & 0.67 & 19 & State orders limiting the project & 0.43 \\
\hline 26 & New solutions replacing the initial project & 0.67 & 8 & Failures in management; insufficient interest on the & 0.42 \\
\hline 22 & Unfavorable price relations & 0.66 & & part of managers & \\
\hline 15 & Conservative and obsolete views & 0.65 & & & \\
\hline 14 & Insufficient technological and qualitative level & 0.57 & \multicolumn{3}{|l|}{ Factor 6} \\
\hline 23 & Insufficient special knowledge & 0.74 & 4 & Insufficient supply of machines and means of & 0.58 \\
\hline 16 & Inexact and changing objectives & 0.68 & & rationalization & \\
\hline 10 & Differences of opinion between managers and experts & 0.66 & 13 & High costs; planned economy not reached & 0.50 \\
\hline 7 & Lack of personnel in research and development & 0.63 & & & \\
\hline 18 & Changing demand & 0.50 & \multicolumn{3}{|l|}{ Factor 7} \\
\hline \multirow[t]{2}{*}{14} & Insufficient technological and qualitative level & 0.45 & 9 & Long time required by managers for coordination & 0.68 \\
\hline & & & 8 & $\begin{array}{l}\text { Failures in management; insufficient interest on the } \\
\text { part of managers }\end{array}$ & 0.44 \\
\hline
\end{tabular}


activities. We identified three other important determinants, the economic mechanism (including price relations, planning mechanisms, and other incentives), know-how, and cost. Our improved scheme for factor analysis is shown in Table 24, which illustrates the complexity of innovation management.

\subsubsection{Using Factor Profiles in Comparing Enterprises}

While the number of innovations analyzed was too small to allow us to draw further conclusions, it became clear to us that the 32 firms we investigated did not sufficiently develop innovative potential. The influence of both factors inhibiting innovation and factors promoting innovation in a given firm can be described by a profile. We also discovered that the objective factor configuration is far more unified than is the specific behavior of firms. This finding suggests that we should pay more attention to the objective factor configuration of the innovation process according to industry, to the national economy, and to basic innovations and improvement-related innovations. On the other hand, we should analyze the individual behavior of firms and compare our results with the objective factor configuration on the level of the industry or society; this could provide us with information, not only about the firm's management, but also about national policy for innovation.

The consequences of an inadequate policy for innovation in an industrial firm are not always immediately apparent. It may also take a long time to develop and to use creative potential. Managers should give the greatest attention to the human factor and to the appropriate combination of important factors. We propose investigating this problem by a specific profile showing the strength of factors inhibiting innovation and of a firm's own activities in promoting innovation during the innovation process. Figure 13 shows such a profile for the sampled 32 firms in sectors of the consumer goods industry.

We note the greatest differences between the strength of factors inhibiting innovative activities and the strength of the firm's own capabilities in the following determinants and stages:

-.- Cooperation and coordination: research and development

- Innovative potential: production

-- Know-how: production

Capacity for mastering ongoing processes: marketing

Therefore, a long-term development program for a given industry should include measures for improving organization in research and development and for increasing the qualification level in production. Current organizational changes in industry in the GDR have the explicit goal of mastering the complexity of the innovation process and enabling firms to implement their new products and processes without bureaucratic delays. In this process, exchange of experience between enterprises plays an important role.

Comparison of enterprises is an effective tool for recognizing both bottlenecks and opportunities. For example, Fig. 14, which compares a single firm's profile with the average of the investigated sample, shows that the firm under consideration might have experience in marketing that would be useful for other enterprises. Comparison of enterprises was formerly oriented primarily toward technical and economic indicators. Comparison of determinants of the innovation process, innovative potential, and know-how could be a useful addition to these traditional tools of management.

Profiles enable us to trace major gaps and bottlenecks and to discover possible directions for further investigation of obstacles and factors blocking innovative activities, thus 
TABLE 24 Determinants and factors at various stages of the innovation process, as measured by 26 variables.

\begin{tabular}{|c|c|c|c|c|c|c|c|c|c|c|c|c|c|c|}
\hline \multirow[b]{3}{*}{ Stage } & \multicolumn{14}{|c|}{ Determinant and factor } \\
\hline & \multicolumn{2}{|c|}{$\begin{array}{l}1 \text { lnnovative } \\
\text { potential }(I)\end{array}$} & \multicolumn{2}{|c|}{$\begin{array}{l}2 \text { Strategic } \\
\text { orientation }(S)\end{array}$} & \multicolumn{2}{|c|}{$\begin{array}{l}3 \text { Cooperation and } \\
\text { coordination }(C)\end{array}$} & \multicolumn{2}{|c|}{$\begin{array}{l}4 \text { Capacity for } \\
\text { mastering ongoing } \\
\text { processes }(O)\end{array}$} & \multicolumn{2}{|c|}{$\begin{array}{l}5 \text { Economic } \\
\text { mechanism }(E)\end{array}$} & \multicolumn{2}{|c|}{6 Know-how $(K)$} & \multicolumn{2}{|l|}{ All } \\
\hline & $p$ & $q$ & $p$ & $q$ & $p$ & $q$ & $p$ & $q$ & $p$ & $q$ & $p$ & $q$ & $p$ & $q$ \\
\hline Research and development & $\begin{array}{r}11 \\
7 \\
15 \\
25 \\
24 \\
19 \\
(1)\end{array}$ & & $\begin{array}{r}7 \\
14 \\
17\end{array}$ & $\begin{array}{c}17 \\
20 \\
12 \\
11 \\
15 \\
1 \\
(1)\end{array}$ & $\begin{array}{r}24 \\
21 \\
4 \\
26 \\
12 \\
(3)\end{array}$ & $\begin{array}{l}25 \\
24 \\
26 \\
22 \\
15 \\
14 \\
(2)\end{array}$ & $\begin{array}{l}3 \\
7\end{array}$ & & & & $\begin{array}{r}5 \\
12 \\
20 \\
23\end{array}$ & & & \\
\hline Production & $\begin{array}{r}6 \\
13 \\
23\end{array}$ & $\begin{array}{r}6 \\
14 \\
13 \\
(6)\end{array}$ & $\begin{array}{l}16 \\
20 \\
24\end{array}$ & & & & $\begin{array}{r}3 \\
13 \\
21\end{array}$ & & & & $\begin{array}{r}6 \\
20 \\
23\end{array}$ & & & \\
\hline All (management) & $\begin{array}{r}8 \\
10 \\
15\end{array}$ & & $\begin{array}{r}18 \\
16 \\
1 \\
17 \\
12 \\
(2)\end{array}$ & $\begin{array}{r}23 \\
16 \\
10 \\
7 \\
18 \\
14 \\
(3)\end{array}$ & $\begin{array}{r}4 \\
21 \\
1 \\
13 \\
(4)\end{array}$ & $\begin{array}{r}4 \\
21 \\
1 \\
13 \\
(4)\end{array}$ & $\begin{array}{l}13 \\
21 \\
19 \\
(6)\end{array}$ & $\begin{array}{c}3 \\
10 \\
14 \\
19 \\
8 \\
(5)\end{array}$ & $\begin{array}{r}22 \\
3 \\
19 \\
(4)\end{array}$ & & $\begin{array}{r}6 \\
2 \\
23 \\
20 \\
(5)\end{array}$ & & $\begin{array}{r}8 \\
10 \\
5 \\
(7)\end{array}$ & $\begin{array}{r}9 \\
8 \\
(7)\end{array}$ \\
\hline
\end{tabular}

NOTES

$p=$ variables inhibiting innovative activities.

$q=$ variables promoting innovative activities

Numbers in parentheses are factor numbers.

Figures in factor fields are variables from multivariate analysis.

Numbers in italics show other appropriate variables.

The cost factor is omitted because it is of little importance. 


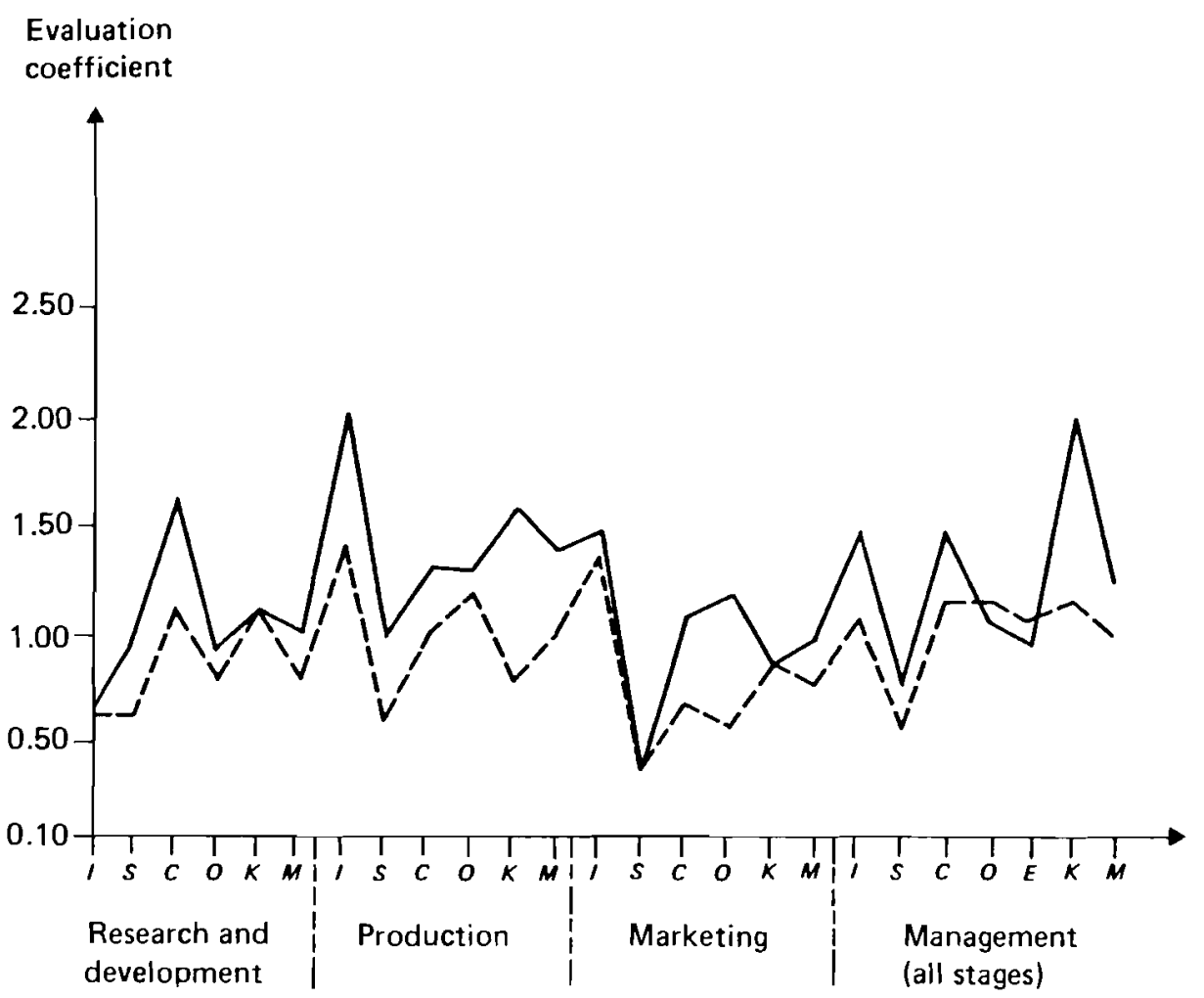

FIGURE 13 Profile of the strength of factors inhibiting innovative activities ( - - - ) and factors promoting innovative activities ( $\ldots$ ) in 32 firms (average), where $I$ is innovative potential, $S$ is strategic orientation, $C$ is cooperation and coordination, $O$ is capacity for mastering ongoing processes, $E$ is economic mechanism, $K$ is know-how, and $M$ is mean value.

providing an instrument for management at the corporate level. Under a planned economy, exchange of experience and competition between teams of workers in outbidding planned figures play an important role. A firm's profile further explains the quantitative indicators of efficiency. On the other hand, we can assume that profiles show significant differences among branches of industry and among stages of the efficiency cycle. Progression through take-off, rapid growth, maturation, saturation, and decline is connected with structural changes, which should be planned at upper levels of management.

\subsection{Innovation and the Efficiency Cycle}

Our investigation of the roles of basic and improvement-related innovations and our analysis of the life cycles of industrial organizations can help us to understand better why the innovation process is not continuous as we might first assume; rather, it is interrupted by the effects of stimulation or its absence. The relationship between basic and improvementrelated innovations drives the process of technological and economic development. This relationship is at the core of the special circumstances surrounding the birth, growth, and decline of each successive new branch of industry. Simple demand pull models or technci ogy push models are therefore inadequate explanations of the innovation process - in 


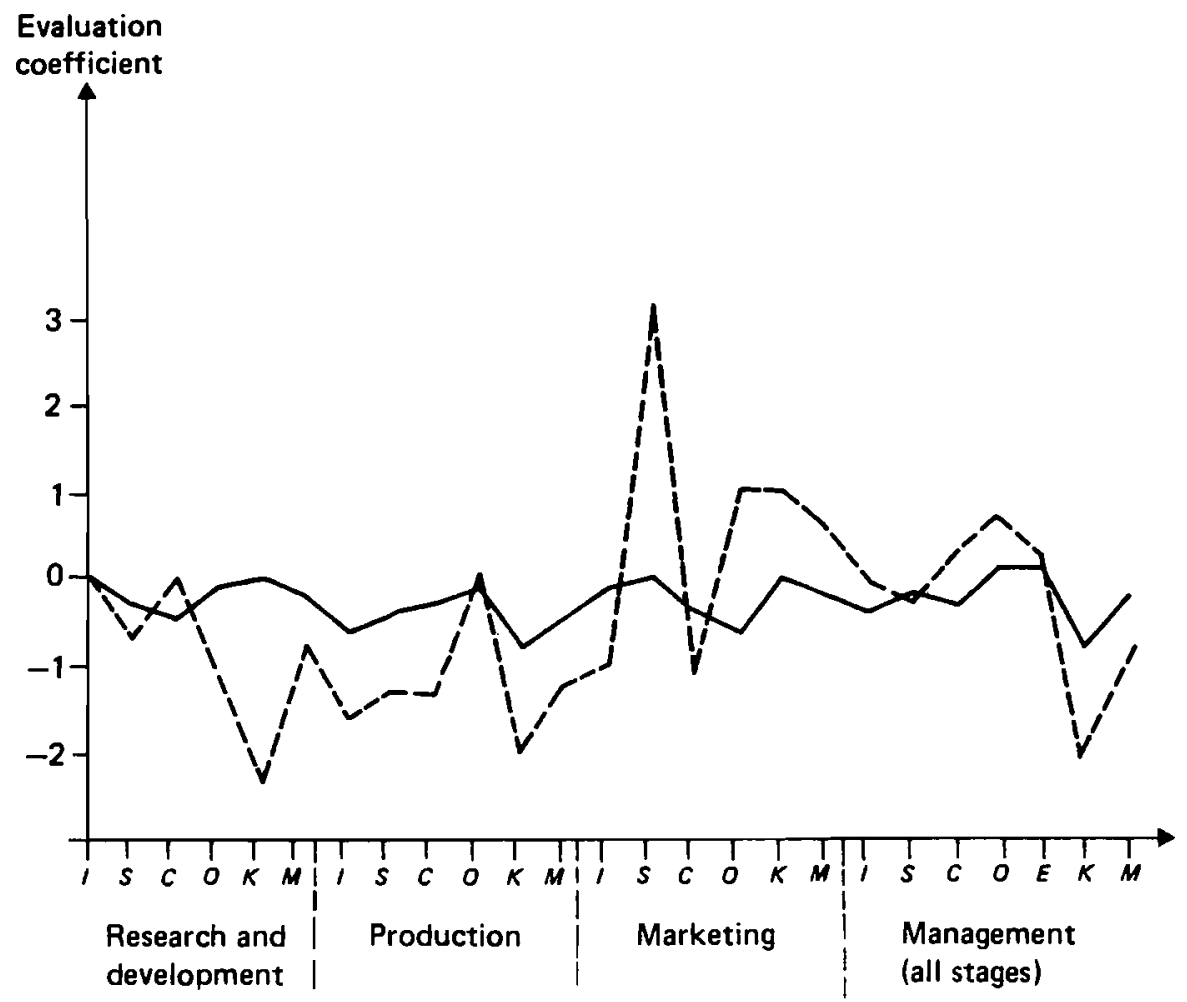

FIGURE 14 Difference between strength of factors inhibiting and strength of factors promoting innovative activities for average of 32 firms (-_-) and firm $27(\ldots)$, where $I$ is innovative potential, $S$ is strategic orientation, $C$ is cooperation and coordination, $O$ is capacity for mastering ongoing processes, $E$ is economic mechanism, $K$ is know-how, and $M$ is mean value.

specific branches of manufacturing industry or in the economy as a whole. The interaction between science, technology, and the economy varies in its nature and intensity over time and among various industries.

We cannot say that inventions are always the simple result of demand pull. Need and demand are the main driving factors in the diffusion process. When we look at the innovation process in retrospect, we find that inventions are all caused by an existing need, but the more important ones came from a rather probabilistic cognitive process that led to the achievement of goals that had not previously been realized. Penicillin, saccharin, and synthetic rubber are examples. At the end of the invention process, needs that were not the original targets of research and developinent were satisfied. Often demand pull is the main reason that incremental innovations use the efficiency potential of basic innovation. But fundamental inventions are less (or not as directly) connected with market demand or concrete needs. Basic innovations create new fields for production and efficiency through, say, a series of new scientific discoveries and technological advances. The connection between these advances and the developing needs of society is often realized slowly. The role of basic innovations in the development of efficiency is demonstrated through Fig. 15.

We turn now to the impact of basic and inprovement-related innovations on the economy. Efficiency in general is 


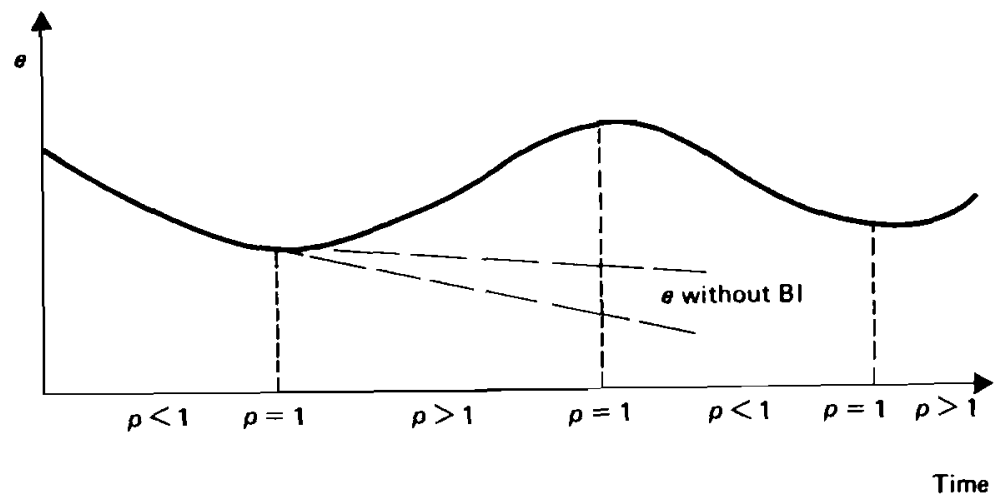

FIGURE 15 Role of basic innovations in the development of efficiency, where $e$ is relative efficiency, $\mathrm{BI}$ is basic innovation, and $p$ is given by eqs. (28) and (29).

$$
e_{0}=E_{0} / C_{0}
$$

where

$E_{0}$ is the sum of benefits or revenues at time $t=0$

$C_{0}$ is the sum of costs or expenditures at time $t=0$

At $t=1$ we find

$$
\begin{aligned}
& e_{1}=\frac{E_{0}+\Delta E}{C_{0}+\Delta C}=e_{0} \frac{1+\Delta E / E_{0}}{1+\Delta C / C_{0}} \\
& \Delta E=E_{1}-E_{0} \\
& \Delta C=C_{1}-C_{0}
\end{aligned}
$$

The increase of $E$ can be divided into

$$
\Delta E=\Delta E_{N}+\Delta E_{A}
$$

where

$\Delta E_{N}$ is the increase in benefits or revenues from new processes and products $\Delta E_{A}$ is the increase in benefits or revenues from old processes and products

At the same time, for costs

$$
\Delta C=\Delta C_{N}+\Delta C_{A}
$$

Therefore 


$$
\begin{aligned}
& e_{1}=e_{0} \frac{1+\left(\Delta E_{N}+\Delta E_{A}\right) / E_{0}}{1+\left(\Delta C_{N}+\Delta C_{A}\right) / C_{0}} \\
& e_{1}=e_{0} p
\end{aligned}
$$

A pure improvement policy gives us $\Delta E_{N}=0$ and $\Delta C_{N}=0$. However, initially we have high benefits $\Delta E_{A}$ in connection with moderate expenditures $\Delta C_{A}$, with $p>1$. Later, we have diminishing returns and thus $p<1$ and a decrease in efficiency.

A pure or dominant policy of improvement leads to a situation described by many authors as a "productivity dilemma," where primary attention is given to short-term gains and new basic innovations do not occur or are delayed. The inertia of the given technological system becomes a major barrier for further economic progress. Therefore, efficiency $e$ declines because of a lack of gains from substantial improvement-related innovations, which may be explained by the inevitable increase in costs for resources, environment, and infrastructure.

This situation is critical for further economic development. If we are unable to stimulate inventions that can open new directions and fields of economic activity and thus improve efficiency, the result will be predictable: a decline in the ability to meet national and societal needs, to overcome shortages of resources, to avoid unemployment, and to promote the conditions necessary for business activity, especially investment activity. In the case of $p<1$, the innovation process has "run dry" owing to the effects of innovations, which have no positive influence on efficiency, or to improvement-related innovations that cannot compensate for increasing costs. The result is stagnation or resource crises with grave social and political consequences - crises very different from the usual, seven-to ten-year ups and downs in the business cycle of capital reproduction.

\section{CONCLUSIONS}

In this report we have dealt with the concept of relative efficiency. Clearly, innovative efficiency can be measured only by measuring the efficiency of the innovating system, which can be better understood by comparison over time with the efficiency of the next higher system. When there are considerable changes in the efficiency of a national economy as a whole, there are also essential changes in the relative efficiency of a given set of innovations. Changes in the prices of resources have a direct and indirect impact on the efficiency of innovations. Price increases lower the absolute efficiency of innovating systems, but may, on the other hand, improve relative efficiency in some cases.

A dynamic view of efficiency is important for innovation policy. In both market and planned economies, it is necessary to see, not only the bottlenecks and shortcomings, but also the prospects and opportunities offered by a given stage in the efficiency cycle. The efficiency cycle is a challenge for management. Managers should be able and ready to change their approaches according to the requirements of various stages and to master growing complexity of innovation management. We found that the combination of factors influencing innovative efficiency changes considerably and over the entire cycle shifts from the innovating system to the environment. The better the innovating system can master outside problems, the more likely that the innovation will succeed. Here we find also the 
explanation for the striking differences in the importance of factors influencing innovations. Sometimes the principal factors are entrepreneurship and the role of managers; sometimes, the understanding of user needs and marketing; and sometimes, managerial techniques and strength.

Our analysis of different sets of factors revealed that innovative potential, strategic orientation, cooperation and coordination, and know-how are the main determinants for the success of innovations from the standpoint of an industrial organization. These factors should be developed for each stage in the efficiency cycle. Our investigation could not determine the concrete interdependence of these determinants in various stages; this will be a goal for further research. It is obvious, however, that the interface of determinants must be described in terms of policy making and active response to the needs of the given stage in the cycle.

We also think that such traditional means of economic analysis as productivity analysis should be revised from the standpoint of the efficiency cycle and the influence of innovations. Such an analysis must have a more efficient forecasting power and operational value, which can be reached if the analysis answers three questions:

- What change in efficiency can we expect in the future?

- How can we master the requirements of the next stage in the efficiency cycle of the given system?

- How can we combine innovating and noninnovating subsystems to ensure stable growth of efficiency in the industry as a whole?

\section{ACKNOWLEDGMENTS}

We would like to extend our thanks for fruitful discussions and useful hints to Professor Daniel Roman, the George Washington University, Washington, DC; Professor Walter Goldberg, International Institute of Management, Berlin (West);Professor Rolfe Tomlinson, School of Industrial and Business Studies, University of Warwick, UK; Professor Walter Zegveld, Netherlands Organization for Applied Scientific Research (TNO), Delft, the Netherlands; and Professor Nikolai Lapin, Academy of Sciences, USSR.

\section{REFERENCES}

Abernathy, W.J. (1978) The Productivity Dilemma: Roadblock to Innovation in the Automobile Industry. Baltimore and London: Johns Hopkins University Press.

Abernathy, W., and J. Utterback (1978) Patterns of Industrial Innovation. Technology Review 80(7): $40-47$.

Eisendraht, E. (1964) Brutto- und Nettoprinzip in der westlichen und östlichen Wirtschaftsforschung. In Vierteljahreshefte für Wirtschaftsforschung. Berlin (West): Duncker und Humblot.

Energy Systems Program Group of the International Institute for Applied Systems Analysis (1981) Energy in a Finite World: A Global Systems Analysis. W. Häfele, Program Leader. Cambridge, Massachusetts: Ballinger.

Gold, B., ed. (1975) Technological Change: Economics, Management and Environment. Oxford: Pergamon Press.

Goldberg, W. (1980) Stagnation and Innovation: Relevant Policy Questions. DP-80-12. Berlin (West): International Institute of Management.

Haustein, H.-D. (1974) Die Proportionalität der technischen Basis. Berlin (East): A kademie Verlag. In German. 
Haustein, H.-D. (1976) Messung der volkswirtschaftlichen Intensivierung. Berlin (East): Akademie Verlag. In German.

Haustein, H.-D. (1979) Innovations in the Lighting Industry. WP-80-12. Laxenburg, Austria: International Institute for Applied Systems Analysis.

Henriot, I. (1955) Geschichte des Schiffbaus. Leipzig-Jena: Urania Verlag. In German.

Knight, K.E. (1967) A Descriptive Model of the Intra-Firm Innovation Process. Journal of Business 40, October:478-496.

Krengel, R., E. Baumgart, A. Boness, R. Pischner, and K. Droege $(1973,1975,1978)$ Produktionsvolumen und -potential: Produktionsfaktoren der Industrie im Gebiet der BRD. Statistische Kennziffern. Berlin (West): Deutsches Institut für Wirtschaftsforschung.

Maier, H. (1979) Some Conclusions for International Technology Assessment from the IIASA Energy Study. Presented at the Twenty-fourth International Meeting of the Institute of Management Sciences, Honolulu, Hawaii, 18-21 July, 1979.

Mensch, G. (1976) Gemischtwirtschaftliche Innovationspraxis. Göttingen: Otto Schwartz. In German.

Myers, S., and D.G. Marquis (1969) Successful Industrial Innovations: A Study of Factors Underlying Innovation in Selected Firms. NSF 69-17. Washington, DC: US National Science Foundation.

Nelson, R.R., and S.G. Winter (1977) In search of useful theory of innovation. Research Policy 6(1): $36-76$.

Nick, H. (1974) Die Wechselwirkung revolutionärer und evolutionärer Veränderungen. In E. Gatovskij, H. Maier, F. Kutta, Wissenschaft, Technik und Produktion. Wissenschaft, Ökonomie, Fortschritt. Berlin (East): Akademie Verlag. In German.

OECD Economic Outlook (1979)25: July.

Ray, G.F. (1979) Der Innovationsprozess in Westeuropäischen Industrieländern. Innovation in der Energiewirtschaft. Band 3. Berlin (West): Duncker und Humblot. In German.

Schumpeter, J.A. (1952) Theorie der wirtschaftlichen Entwicklung. Berlin (West): Duncker und Humblot. In German.

Science Policy Research Unit of the University of Sussex (1972) Success and Failure in Industrial Innovation: Report on the Project SAPPHO. London: Centre for the Study of Industrial Innovation.

Statistical Yearbook of the USSR (1977) Moscow: Statistika.

Uhlmann, L. (1978) Der Innovationsprozess in Westeuropäischen Industrieländern. Band 2. Der Ablauf industrieller Innovationsprozesse. Berlin (West): Duncker und Humblot. In German.

US National Science Board (1977) Science Indicators 1976: Report of the National Science Board. 1977. NSB-77-1. Washington, DC: US Government Printing Office.

US Energy Research and Development Administration (1976) A National Plan for Energy Research, Development and Demonstration: Creating Energy Choices for the Future. ERDA-48. Washington, DC: US Government Printing Office.

Zvorykin, A.A., N.I. Osmova, V.I. Chernyshev, and S.V. Shukhardin (1962) Istorija tekhniki. Moscow: Gospolitizdat. In Russian.

\section{APPENDIX A A Method for Calculating the Time Needed to Equalize Productivity Levels in Two Countries}

\section{Given}

- The productivity level $Y_{t}$ of countries $A$ and $B$ at time $t=1$

- The average productivity growth rate $\lambda_{m}$ for time period $t=1,2, \ldots, m$ in both countries

- The expected future productivity growth rate $\lambda_{r}$ for time period $t=m, m+1$, $\ldots, m+r$

We can assume

$$
Y^{A}=Y_{1}^{A}\left(1+\lambda_{m}^{A}\right)^{m-1}\left(1+\lambda_{r}^{A}\right)^{r}
$$




$$
Y^{B}=Y_{1}^{B}\left(1+\lambda_{m}^{B}\right)^{m-1}\left(1+\lambda_{r}^{B}\right)^{r}
$$

The growth rate is

$$
\lambda_{m}=\left(Y_{m} / Y_{1}\right)^{1 / m-1}-1
$$

From eq. (A1) = eq. (A2) we arrive at

$$
r=\frac{\ln \left(Y_{1}^{A} / Y_{1}^{B}\right)+(m-1) \ln \left[\left(1+\lambda_{m}^{A}\right) /\left(1+\lambda_{m}^{B}\right)\right]}{\ln \left[\left(1+\lambda_{r}^{B}\right) /\left(1+\lambda_{r}^{A}\right)\right]}
$$

This equation is meaningful if

$$
\begin{aligned}
& Y_{1}^{A}>Y_{1}^{B} \\
& \lambda_{r}^{B}>\lambda_{r}^{A} \\
& \Delta \lambda=\lambda_{r}-\lambda_{m}
\end{aligned}
$$

and

$$
\begin{aligned}
& \Delta \lambda^{B}>\Delta \lambda^{A} \\
& r=\frac{\ln \left(Y_{1}^{A} / Y_{1}^{B}\right)+(m-1) \ln \left[\left(1+\lambda_{m}^{A}\right) /\left(1+\lambda_{m}^{B}\right)\right]}{\ln \left[\left(1+\lambda_{m}^{B}+\Delta \lambda^{B}\right) /\left(1+\lambda_{m}^{A}+\Delta \lambda^{A}\right)\right]}
\end{aligned}
$$

Substituting

$$
\begin{aligned}
& \ln \left(Y_{1}^{A} / Y_{1}^{B}\right)=C \\
& 1+\lambda_{m}=i_{m}
\end{aligned}
$$

We can write eq. (A7) as follows:

$$
r=\frac{C+(m-1) \ln \left(i_{m}^{A} / i_{m}^{B}\right)}{\ln \left[\left(i_{m}^{B}+\Delta \lambda^{B}\right) /\left(i_{m}^{A}+\Delta \lambda^{A}\right)\right]}
$$

In practical cases, $C, m, i_{m}^{A}$, and $i_{m}^{B}$ are given. For $\Delta \lambda^{B}$ and $\Delta \lambda^{A}$ we can assume a first estimation over time period $r^{*}$. By calculating eq. (A11), we arrive at a first approximation of $r_{1}$. Then we must compare $r_{1}$ and $r^{*}$. If $r_{1} \leqslant r^{*}$, there is obviously no problem. But if $r_{1}>r^{*}$, we should decide whether there is any reason for improving the $\Delta \lambda$ assumed. We then arrive at a second approximation of $r$.

Iteration continues until

$$
r_{n}-r_{n-1} \leqslant p
$$


We assume that

$$
\begin{aligned}
& p=1 \text { in forecasts of } 1 \text { to } 5 \text { years } \\
& p=2 \text { in forecasts of } 6 \text { to } 10 \text { years } \\
& p=5 \text { in forecasts of } 11 \text { to } 20 \text { years } \\
& p=10 \text { in forecasts of more than } 20 \text { years }
\end{aligned}
$$

The iteration process is as follows:

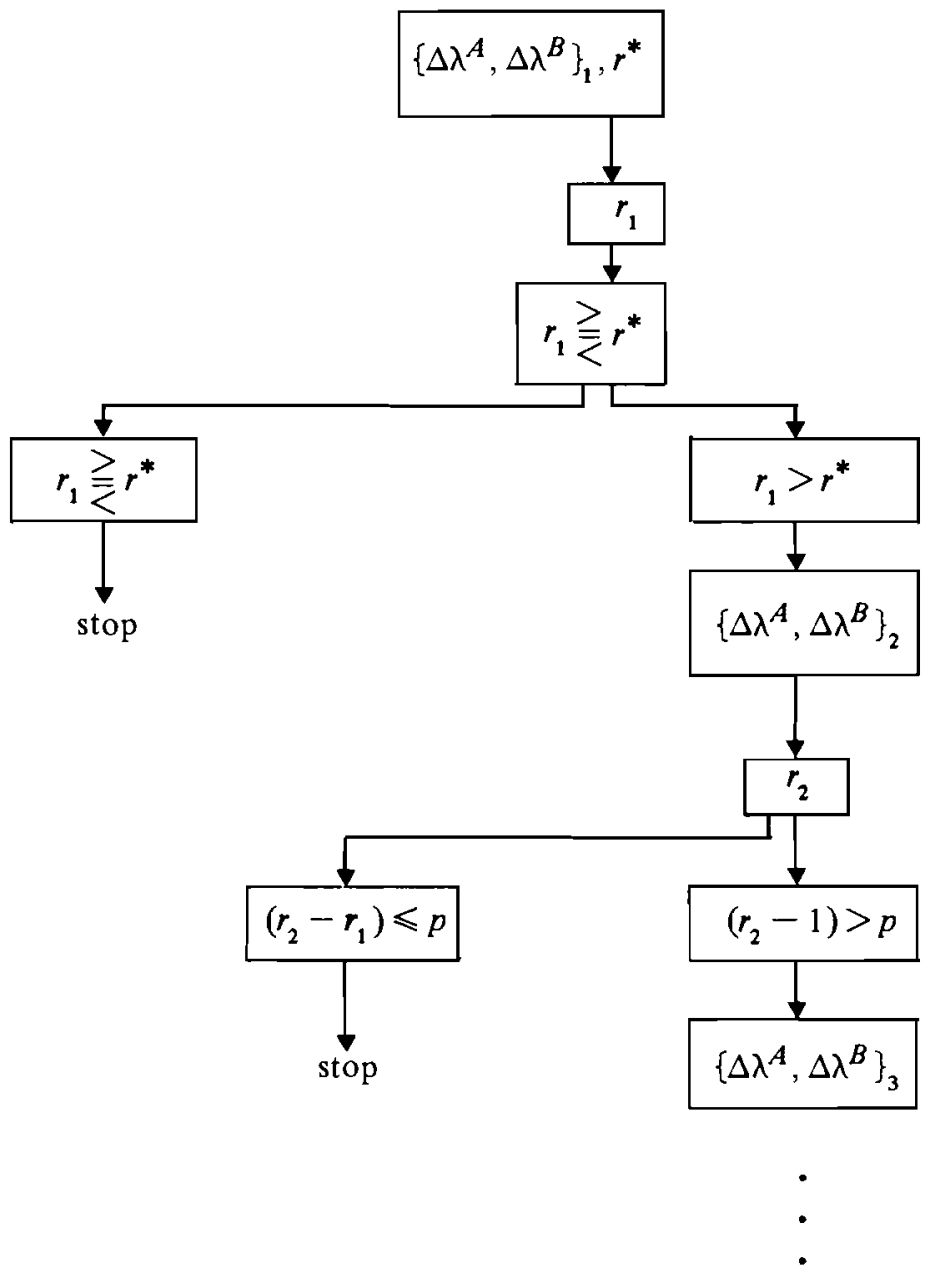




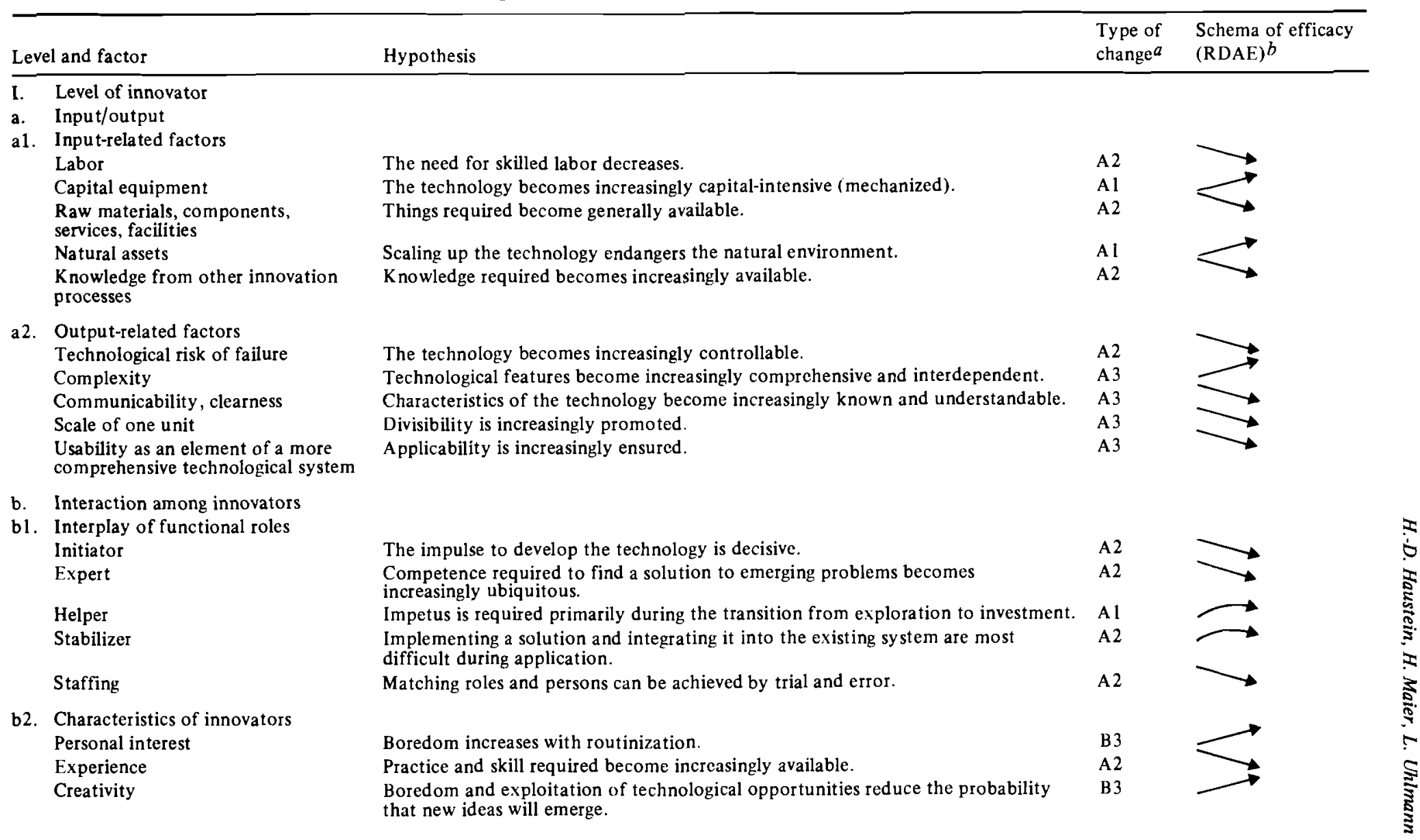


II. Level of organization

c. Resources

Labor

Capital equipment

Financial funds

Natural assets

Raw materials, components

services, facilities

Infrastructure of facilities

Access to knowledge

d. Organizational dimensions

dl. Relationships with the environment

Branch of industry

Position in market

Response to client's needs

Response to technological

trajectories

Response to economic and social trajectories

d2. Internal dimensions

Size of the organization

Ownership, influence of mother companies

System of goals

Technological and innovative

philosophy (innovativeness)

Decision-making principles

Principles of budgeting

Principles of planning

System of incentives

System of sanctions

\section{Job allocation}

Principles of training and professional developmen
Dependence on the availability of manpower decreases.

The technology becomes increasingly capital-intensive (mechanized).

Funds needed increase because of scaling up.

Scaling up the technology endangers the natural environment.

Things required become generally available.

Facilities are generally improved and adjusted to requirements.

Knowledge required becomes increasingly available.

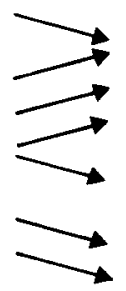

The influence of the branch alone cannot be estimated.

The influence of a strong or a weak position alone cannot be estimated.

Needs and applicability of the technology match more and more.

Future technological features become increasingly clear.

Future economic and social features become increasingly clear.

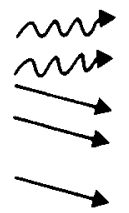

The influence of size alone cannot be estimated.

wo

The influence of ownership alone cannot be estimated.

The technology is increasingly included in the organization's system of goals.

The technology's compatibility with the organization's philosophy is examined

during the early stages of the innovation process.

The influence of the decision-making habit alone cannot be estimated.

Problems related to including the technology in the budget become increasingly easily solved.

Increasing clearness makes planning easier.

Labor input becomes decreasingly important.

Imposing penalties in the case of inability to promote innovation becomes mor important as work progresses.

Combining manpower and activities becomes increasingly easy.

Problems occur primarily during the early stages of the innovation process. 


\begin{tabular}{|c|c|c|c|c|}
\hline \multicolumn{2}{|c|}{ Level and factor } & \multirow{2}{*}{$\begin{array}{l}\text { Hypothesis } \\
\text { Problems related to the internal social climate that may arise when the technology } \\
\text { becomes important may be settled by its acceptance. }\end{array}$} & \multirow{2}{*}{$\begin{array}{l}\text { Type of } \\
\text { change }\end{array}$} & \multirow{2}{*}{$\begin{array}{l}\text { Schema of efficacy } \\
\text { (RDAE) } b\end{array}$} \\
\hline & Internal social climate & & & \\
\hline & Formal organizational principles & $\begin{array}{l}\text { Implementing the technology may cause problems in the existing organizational } \\
\text { structure. }\end{array}$ & Al & 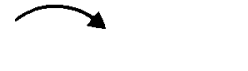 \\
\hline \multirow[t]{6}{*}{$\begin{array}{l}\text { e. } \\
\text { el. }\end{array}$} & $\begin{array}{l}\text { Organizational measures } \\
\text { Planning measures }\end{array}$ & & & \\
\hline & $\begin{array}{l}\text { Objectives in pursuing the } \\
\text { technology }\end{array}$ & The influence of the objectives alone cannot be estimated. & - & $\rightarrow$ \\
\hline & Selection of projects & The more the technology is understood, the more easily decisions may be made. & A3 & \\
\hline & $\begin{array}{l}\text { Evaluation and forecasting of costs } \\
\text { and benefits }\end{array}$ & The more experience is gained, the less difficult the problem is. & A2 & \\
\hline & $\begin{array}{l}\text { Determination of interaction among } \\
\text { innovators }\end{array}$ & $\begin{array}{l}\text { Assigning roles to persons is more difficult during the early stages of the innovation } \\
\text { process. }\end{array}$ & A2 & \\
\hline & Target setting for innovators & Regulating time and resources becomes easier as the technology becomes clearer. & A3 & \\
\hline \multirow[t]{3}{*}{ e2. } & $\begin{array}{l}\text { Control measures } \\
\text { Supervision of innovative activities }\end{array}$ & $\begin{array}{l}\text { The need for and difficulties of supervision are greatest in "open" stages, where } \\
\text { there are several ways to proceed. }\end{array}$ & A2 & \\
\hline & $\begin{array}{l}\text { Decision on solutions proposed by } \\
\text { innovators }\end{array}$ & A decision's influence depends on its determinants. & - & \\
\hline & Utilization of knowledge acquired & $\begin{array}{l}\text { The clearer the technology becomes, the easier it is to decide how to use and } \\
\text { transfer knowledge. }\end{array}$ & A2 & \\
\hline \multirow{9}{*}{$\begin{array}{l}\text { III. } \\
\text { f. }\end{array}$} & Level of environment & & & \\
\hline & Resources & & & \\
\hline & Labor & The need for skilled labor decreases. & A2 & \\
\hline & Capital equipment & The technology becomes increasingly capital-intensive (mechanized). & A 1 & \\
\hline & Financial funds & Funds needed increase due to scaling up. & A 1 & \\
\hline & Natural assets & Scaling up the technology endangers the natural environment. & Al & \\
\hline & $\begin{array}{l}\text { Raw materials, components. } \\
\text { services, facilities }\end{array}$ & Things required become generally available. & A2 & \\
\hline & Infrastructure of facilities & $\begin{array}{l}\text { Facilities that the environment must provide become increasingly important as the } \\
\text { technology is scaled up. }\end{array}$ & A 1 & \\
\hline & Funds of and access to knowledge & Knowledge required becomes increasingly available. & A2 & \\
\hline
\end{tabular}


g. Environmental dimensions

g1. Economic sector

Size of the economy

Degree of division of labor

System of competition

International economic engagement

The influence of size alone cannot be estimated.

The influence of increasing specialization alone cannot be estimated.

Competition becomes increasingly relevant as the technology is scaled up.

The influence of international trade alone cannot be estimated.

Political sector

National goals

Consistency with the system of national goals becomes increasingly relevant as the technology requires more and more resources.

Allocation of political power System of facilities for research and development

The influence of the allocation of competence cannot be estimated.

Influence is especially relevant during research and development.

Social sector System of social values

Social attitude toward new technologies

h. Environmental measures

h1. Economic sector

Development of demand, economic prospects

Competing technologies

Cooperation with suppliers

Cooperation with buyers

Agreements with competing firms

Wages

Prices of capital equipment

Prices of raw materials

components, services, facilities

Environmental effects

Social values become increasingly relevant as the technology is exposed to the public.

Social acceptance becomes increasingly relevant as the technology is exposed to the public.

A 1

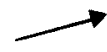

mos

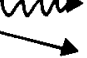

Revenues achievable from the technology

Demand must first be created; it is then matched and is increasingly exhausted.

Advantages of the technology against those of other emerging technologies are increasingly lost.

Dependence on suppliers' know-how decreases.

The need to inform and help buyers is most important during the early stages of application.

The difficulties and effects of making agreements with competing firms cannot be estimated.

Wages have their greatest influence during the early stages of application

The more capital-intensive the technology becomes, the more important the

costs of capital usage are.

Dependence on the costs of goods input increases with the emergence of

competing firms and technologies.

Scaling up the technology leads increasingly to problems with the natural environnent.

After passing the break-cven point, profits decrease with augmenting exploitation.

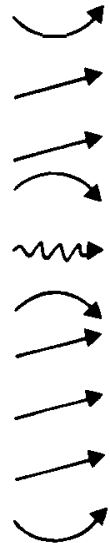




\begin{tabular}{ll} 
Level and factor & Hypothesis \\
\hline h2. $\begin{array}{l}\text { Political sector } \\
\text { Regulations }\end{array}$ & $\begin{array}{l}\text { Regulations imposed by authorities are most relevant during the early stages of } \\
\text { application. } \\
\text { Taxation becomes increasingly relevant as the technology is scaled up. } \\
\text { Taxes }\end{array}$ \\
$\begin{array}{l}\text { Government grants } \\
\text { Government incentives }\end{array}$ & $\begin{array}{l}\text { The influence of government incentives alone cannot be estimated. } \\
\text { (RDAE) } b\end{array}$ \\
$\begin{array}{l}\text { Social sector } \\
\text { Public familiarity with the } \\
\text { technology }\end{array}$ & The technology becomes increasingly known to the public. \\
$\begin{array}{l}\text { Attitude toward the technology } \\
\text { image }\end{array}$ & $\begin{array}{l}\text { Social acceptance of the technology becomcs increasingly rclevant. } \\
\text { Lack of recognition is most restrictive in the early stages. }\end{array}$
\end{tabular}

a See Sections 2.2.2 and 2.3.2 for explanation.

$b$ See Sections 2.3.1 and 2.3.2 for explanation. 


\section{THE AUTHORS}

Heinz-Dieter Haustein received his diploma in Industrial Economics in 1955 from the Leningrad Institute of Finance and Economics and his Ph.D. in 1960 and his Habilitation in 1964 from the University of Economics, Berlin (East). Deputy Director of the Institute for Management and Head of the Department for Planning and Forecasting of Science and Technology at the Bruno Leuschner University of Economics in Berlin (East), Professor Haustein has been working on the Innovation Management Task of the Management and Technology Area at IIASA since 1979. His research interests include the economic analysis of technology and innovation.

Harry' Maier graduated in 1957 from the Humboldt University in Berlin (East) and received his $\mathrm{Ph} . \mathrm{D}$. in 1961 and his Habilitation in 1967 from the same university. He is Deputy Dircctor of the Central Institute of Economic Sciences of the Academy of Sciences of the German Democratic Republic. Professor Maier worked in IIASA's Management and Technology Area from 1978 until 1980. His scientific interests include the economics of education and governmental policy with respect to technology.

Luitpold Uhlmann graduated in 1961 from the University Erlangen-Nürnberg and later received his Ph.D. from the same university. He worked for IBM from 1962 to 1965 ; since 1965 he has been a Research Scientist in the IFO--Institute for Economic Research in Munich. His scientific interests include the economic and social problems of technological change. 
